\title{
An Integral Numerical Analysis of Impact of a Commercial Aircraft on Nuclear Containment
}

\author{
Xiaoxin Wang (D), Qin Zhou $(\mathbb{D}$, Li Shi $(\mathbb{D}$, Haitao Wang $(\mathbb{D}$, and Xiaotian Li \\ Institute of Nuclear and New Energy Technology, Collaborative Innovation Center of Advanced Nuclear Energy Technology, \\ Tsinghua University, Key Laboratory of Advanced Reactor Engineering and Safety of Ministry of Education, \\ Beijing 100084, China \\ Correspondence should be addressed to Li Shi; shili@mail.tsinghua.edu.cn
}

Received 3 July 2019; Revised 1 September 2019; Accepted 6 September 2019; Published 13 October 2019

Academic Editor: Michael I. Ojovan

Copyright ( 12019 Xiaoxin Wang et al. This is an open access article distributed under the Creative Commons Attribution License, which permits unrestricted use, distribution, and reproduction in any medium, provided the original work is properly cited.

\begin{abstract}
After the September 11 attack, the resistant capability of containments against aircraft impacts is required to be assessed for newly constructed nuclear power plants (NPPs). In this paper, the crash of a commercial airplane Boeing 767-200ER on the reinforced concrete containment building of an NPP is analyzed using the missile-target interaction method. Two plane models with the same total weight but different fuel distribution are analyzed. The force-time history obtained by FEA (finite element analysis) is compared with the one calculated by the Riera function. In the integral analysis, the mesh sensitivity of the reinforced concrete containment model is studied, and recommendations are provided on the modelling of containment. The impact phenomenon and damage on the containment are investigated through the validated model. The fuel distribution in the aircraft is found to have strong influence on the damage of the containment, which indicates that the load distribution in the transverse direction is critical in the analysis of aircraft impact. The classic load-time function analysis is unable to incorporate this factor and may not be adequate to provide satisfactory results. For this reason, the application of an integral analysis is advantageous in the safety assessment of aircraft impact.
\end{abstract}

\section{Introduction}

Safety assessment of nuclear power plants subjected to aircraft impact has become a research focus since the terrorist attack in September 11. After the accident, the U.S. Nuclear Regulatory Commission [1] and IAEA [2] have established requirements and safety standards in the design of NPPs to protect the integrity of the containment against deliberate and accidental aircraft crash that is expected during the plant lifetime.

Two approaches are provided by the NRC [1] to evaluate the aircraft impact response of NPP containments. The first is a decoupled method called the load-time function method, in which the aircraft impact force and response of the containment are calculated in separate steps. The second is an integral method called missile-target interaction analysis, in which the coupled model of the aircraft and containment is solved in a single step [3].
Riera [4] developed a one-dimensional model to calculate the impact force of aircrafts striking on rigid flat targets assuming conservation of momentum. The load-time functions of various types of commercial and military aircrafts including A707-320, A320, Boeing 747, Boeing 767400, and Phantom F4 were obtained using theoretical, numerical, or experimental methods [5-8]. Containment capacities to withstand these aircraft loadings were widely studied by researchers using load-time function methods [9-12]. The decoupled method has limitations in evaluating impact scenarios with complexity, such as striking with incident angles. Moreover, the impact area where the load is applied to is not easy to determine. The impact area varies from $1.5 \mathrm{~m}^{2}$ to $784 \mathrm{~mm}^{2}$ in various researches [3], which may result in different response results especially in the local damage. Therefore, the integral method was adopted in many recent studies [5-7, 13, 14]. Siefert and Henkel [5] and Zhang et al. [13] carried out analysis using both methods and 
concluded by comparison that the displacement response calculated by the load-time function method is smaller than that by the integral method. Therefore, the application of the integral method is recommended for complex impact scenarios in the design of NPPs.

A wide range of aspects in aircraft impacts were investigated in the recent years. Impact simulations with different geometrical parameters including containment radius, angle of incidence, and impact location were carried out. The influence of these parameters on the global damage response was studied in detail. Abbas et al. [9] observed that the horizontal strike near the junction of a dome and a cylinder is the most critical location. Iqbal et al. [12] and Zhang et al. [13] found that the displacement is the maximum when the crash location is at the midheight of containment (i.e., about $2 / 3$ of the height of the cylinder). Zhang et al. [13] also concluded that the increasing impact velocity as well as decreasing impact angle, wall thickness, and reinforcement ratio results in an increase of impact displacement. Zhang et al. [15] found that the circular section shape of the target decomposes the impact velocity and weakens the impact force and modified the Riera function by including the effect of the dimensionless ratio of nuclear containment radius and aircraft wingspan. Mei et al. [16] and Shin et al. [17] focused on the dynamic vibration response to the aircraft impact.

Damage on containments caused by aircraft impact was evaluated for a number of NPPs. Local or global failure of the containment was observed in several studies. Lo Frano and Forasassi [10] performed a numerical analysis of a Boeing 747-400 aircraft impact into an IRIS containment structure. The results indicated that the outer containment wall was likely to experience local damage, although the overall stability of the containment structure was warranted. Sadique et al. [11] showed that global failure occurred in the Indian BWR Mark-III-type nuclear power plant when it was hit by Boeing 747-400 and Boeing 767-400 aircrafts, while only local damage was observed when it was hit by A320 and A707-320. Thai and Kim [7] analyzed the influence of aircraft impact on the auxiliary building as well as the equipment in the building and found that the global and local structural safety of the building was ensured, but the safety of the equipment was not warranted because of the excessive vibration of the building.

In the damage assessment of containments, the mesh size and quality of the containment model are essential for the reliability of the calculated results. In the OECD-NEA Benchmark Project IRIS, which has validated the finite element method for predicting the outcome of missile impact tests realistically, the number of elements through wall thickness was larger than 10 for most of the studies. However, in the missile-target interaction analysis in the literature, only 4 elements through wall thickness were used in the containment model because of the large computational complexity and consumption for an integral analysis. A mesh convergence study was carried out by Sadique et al. [11] for a load-time function analysis. However, studies on mesh sensitivity have not been reported in missile-target analysis, and the validity of coarse models with 4 elements through wall thickness still remains in doubt.
In this study, the crash of a commercial airplane Boeing 767-200ER on a reinforced concrete containment was simulated using the missile-target interaction method. Two Boeing 767-200 models with the same fuel weight but fueled in different tanks were used in the crash analysis. First, the impact of the two planes on a rigid wall was simulated to obtain the load-time functions. Then, a missile-target interaction analysis was carried out to simulate the two aforementioned planes on a nuclear containment. The mesh sensitivity of the containment model used in the integral analysis was studied. With the validated model, the impact phenomenon was investigated and the damage in the containment in the two impact scenarios was compared. The integrity of the containment was evaluated by the acceptance criteria for aircraft impacts.

\section{Numerical Modelling}

The impact of Boeing 767-200ER on a containment building is numerically analyzed using the finite element code ABAQUS/Explicit [18]. A detailed FE model of the airplane is developed, and the crash of the airplane on a rigid wall is first calculated in order to validate the airplane model and obtain the load-time function. Then, a missile-target interaction analysis is carried out to investigate the impact phenomenon and assess the damage of the containment during the aircraft impact.

2.1. Modelling of an Aircraft. Boeing 767-200ER is a mid- to large-sized commercial airplane with a length of $48.51 \mathrm{~m}$ and a wingspan of $47.57 \mathrm{~m}$. Its operating empty weight, maximum zero fuel weight, and maximum take-off weight are $82 \mathrm{t}, 114 \mathrm{t}$, and $159 \mathrm{t}$, respectively [19]. The FE model of Boeing 767-200ER developed by Lin et al. [20] shown in Figure 1 is used in the missile-target analysis in the present study. The widely accepted modelling techniques for aircrafts such as those used in A320 [5, 13] and B767-400 [7] are adopted. The model represents the mass and stiffness distribution of the major parts of the airplane. The structural parts including ribs and stingers of the fuselage, wing box and stingers, floor boards, horizontal and vertical tails, engines, and skins are modelled by shell or beam elements. The payload of devices and passengers distributed over fuselage is represented by distributed mass.

It is assumed that the airplane is loaded up to $90 \%$ of maximum take-off weight during the crash; that is, the total weight of the model is $143 \mathrm{t}$, including $29 \mathrm{t}$ of fuel. Two types of fuel distribution are considered in the study. In the first scenario, the airplane is fueled into the left and right main tanks on the wings. In the second scenario, $16 \mathrm{t}$ of fuel is stored in the wing tanks, while the rest is stored in the center auxiliary tank. The two cases are referred to as the wing tank (WT) case and the center tank (CT) case hereafter, respectively. The longitudinal mass distributions for the two cases are shown in Figure 2. Because of the sweep angle of the wings, variation of fuel distribution in the transverse direction inevitably results in a certain difference in the longitudinal mass distribution. 


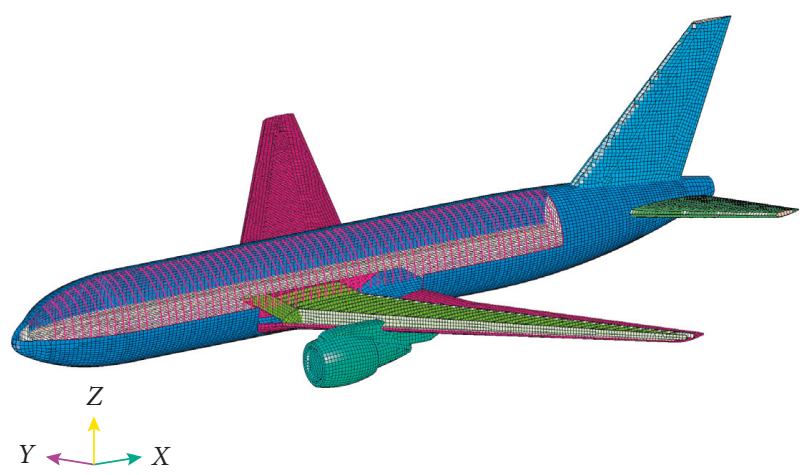

Figure 1: Illustration of the FE model of Boeing 767-200ER.

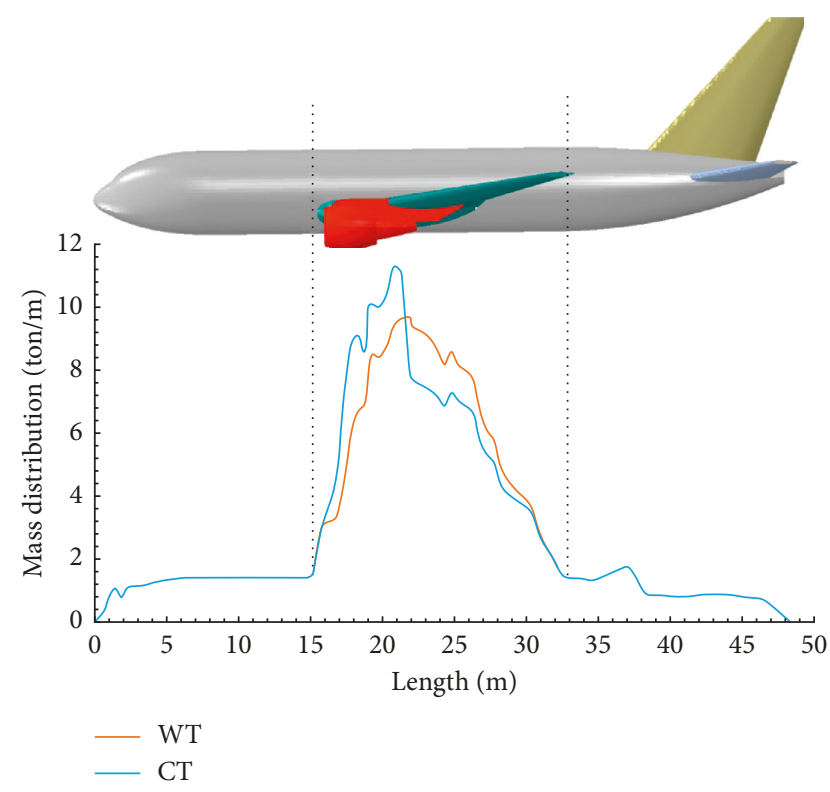

FIgURE 2: Longitudinal mass distribution of Boeing 767-200ER.

The fuel in the airplane is commonly modelled using the added mass method or smooth particle hydrodynamics (SPH) method. Thai et al. [21] found that the impact force slightly increased when the fluid effect was taken into consideration by the SPH method. The increasing factor corresponding to the velocity used in the current study was about 1.25 . Since the weight of the fuel is only about $20 \%$ of the total aircraft weight, the increase in the force due to the fluid effect of the fuel is small. Furthermore, as reported by Shin et al. [17], the difference in the impact force of an aircraft derived by the added mass method and SPH method is acceptable. Therefore, in this paper, the fuel distributed over the fuselage and wing tanks is modelled by distributed mass.

The main structural parts are made of high-strength 2024 aluminum and 1006 steel. The mechanical parameters are listed in Table 1 . The Johnson-Cook plasticity model $[22,23]$ is used to predict the strain and strain rate strengthening behavior of the metals. The stress, strain, and strain rate are related by the following equation:
TABLE 1: Mechanical parameters for the airplane.

\begin{tabular}{lccc}
\hline & $\begin{array}{c}\text { Density } \\
\left(\mathrm{kg} / \mathrm{m}^{3}\right)\end{array}$ & $\begin{array}{c}\text { Young's } \\
\text { modulus }(\mathrm{GPa})\end{array}$ & Poisson's ratio \\
\hline $2024 \mathrm{Al}$ & 2780 & 72.2 & 0.3 \\
1006 steel & 7890 & 200 & 0.3 \\
\hline
\end{tabular}

$$
\sigma=\left(A+B \varepsilon^{n}\right)\left(1+C \ln \dot{\varepsilon}^{*}\right)\left(1-T^{* m}\right),
$$

where $\sigma$ is the effective stress, $\varepsilon$ is the effective plastic strain, $\dot{\varepsilon}^{*}$ is the normalized effective plastic strain rate, and $n$ is the work hardening exponent. $T^{*}$ is defined as $T^{*}=\left(T-T_{0}\right) /\left(T_{\text {melt }}-T_{0}\right)$, where $T, T_{\text {melt }}$, and $T_{0}$ are the current temperature, melting temperature, and room temperature, respectively. $A, B, C$, and $m$ are material constants. The Johnson-Cook dynamic failure model is applied to describe the material damage and failure. Failure is assumed to occur when the damage parameter exceeds 1 . The damage parameter, $D$, is defined as

$$
D=\sum \frac{\Delta \varepsilon}{\varepsilon_{f}},
$$

where $\Delta \varepsilon$ is an increment of the equivalent plastic strain, $\varepsilon_{f}$ is the failure strain, and the summation is performed over all increments in the analysis. The failure strain is given by

$$
\varepsilon_{f}=\left(D_{1}+D_{2} \exp \left(D_{3} \sigma^{*}\right)\right)\left(1+D_{4} \ln \dot{\varepsilon}^{*}\right)\left(1+D_{5} T^{*}\right),
$$

where $\sigma^{*}$ is the pressure-deviatoric stress ratio and the parameters $D_{1}, D_{2}, D_{3}, D_{4}$, and $D_{5}$ are material constants. Once the failure criterion is met, the deviatoric stress components are set to zero and the pressure stress is required to remain compressive for the rest of the calculation. The Johnson-Cook material constants of 1006 steel and 2024 aluminum are listed in Table 2 [24].

2.2. Modelling of a Containment. A typical containment model in a nuclear power plant is used in this study. The containment is composed of a cylindrical wall and a dished head, as illustrated in Figure 3(a). The inside diameter and the total height of the containment are $50 \mathrm{~m}$ and $78 \mathrm{~m}$, respectively. The wall has a constant thickness of $1.5 \mathrm{~m}$ at the cylindrical shell and the dome. The shell is reinforced with $40 \mathrm{~mm}$ diameter bars spaced at a $200 \mathrm{~mm}$ distance at the inner and outer faces of the cylindrical wall as well as the dished head with a concrete cover of $70 \mathrm{~mm}$. The shear reinforcement is provided as $20 \mathrm{~mm}$ diameter bars with a space of $200 \mathrm{~mm}$.

The FE model of the containment building is illustrated in Figure 3. Because of the symmetry in geometry and loading of the containment, only half of the structure is included in the FE model. Symmetric boundary conditions are applied on the symmetry plane. 8-node linear brick elements are used to discretize the concrete. In order to allow for varying sizes of mesh on the containment, an O-grid is constructed on the impact region, as shown in Figure 3(b). Within the "O" region, small-sized and high-quality 
TABLE 2: Johnson-Cook material constants for the airplane.

\begin{tabular}{lccccccccccc}
\hline & $A(\mathrm{MPa})$ & $B(\mathrm{MPa})$ & $C$ & $m$ & $n$ & $T_{\text {melt }}(\mathrm{K})$ & $D_{1}$ & $D_{2}$ & $D_{3}$ & $D_{4}$ & $D_{5}$ \\
\hline $2024 \mathrm{Al}$ & 369 & 684 & 0.0083 & 1.7 & 0.73 & 502 & 0.13 & 0.13 & -1.5 & 0.011 & 0.0 \\
1006 steel & 350 & 275 & 0.022 & 1.0 & 0.36 & 1811 & 0.05 & 3.44 & -2.12 & 0.002 & 0.61 \\
\hline
\end{tabular}

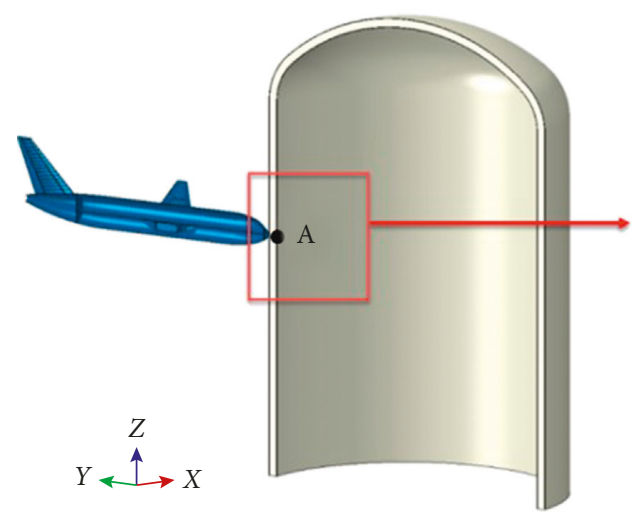

(a)

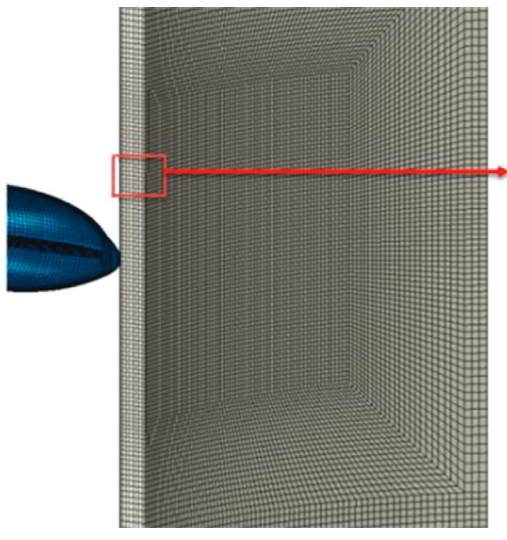

(b)

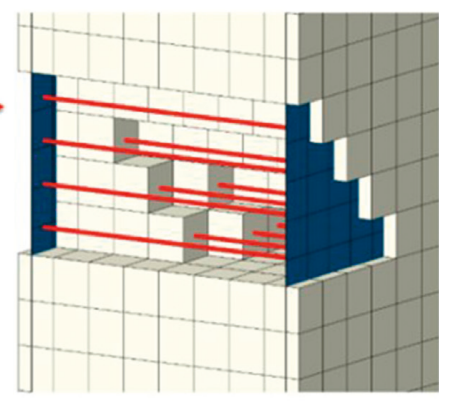

(c)

FIgURE 3: Illustration of the FE model of the containment building.

elements can be generated. Crash analysis of five models with different element sizes is performed to study the mesh sensitivity. The element sizes in the "O" region are $150 \mathrm{~mm} \times 150 \mathrm{~mm} \times 150 \mathrm{~mm}, 200 \mathrm{~mm} \times 200 \mathrm{~mm} \times 200 \mathrm{~mm}$, $250 \mathrm{~mm} \times 250 \mathrm{~mm} \times 250 \mathrm{~mm}, 300 \mathrm{~mm} \times 300 \mathrm{~mm} \times 300 \mathrm{~mm}$, and $375 \mathrm{~mm} \times 375 \mathrm{~mm} \times 375 \mathrm{~mm}$ which give $10,8,6,5$, and 4 elements in the thickness direction, respectively. The element sizes gradually increase to $600 \mathrm{~mm}$ in the faraway region where the influence of the aircraft impact is small for all models.

The bending reinforcement is modelled by rebar layers, shown as blue shells in Figure 3(c), while the shear reinforcement is modelled via truss elements, shown as red bars in Figure 3(c). The concrete and reinforcement are connected to each other using the "embedded region" constraint in ABAQUS. The element size of the reinforcement in the "O" region is similar to or slightly smaller than that of the concrete elements so that each concrete element contains rebars as recommended by ABAQUS. The mesh sizes of concrete and reinforcement for each case are listed in Table 3.

The damaged plasticity model for concrete in ABAQUS is employed to predict the nonlinear behavior and the damage of concrete structures under dynamic loading. Scalar compressive damage $d_{\mathrm{c}}$ and tensile damage $d_{\mathrm{t}}$, which can take values in the range from 0 (undamaged) to 1 (fully damaged), are used to describe the degree of damage. The stress-strain curves under uniaxial compression and tension loading are written as

$$
\begin{aligned}
& \sigma_{\mathrm{c}}=\left(1-d_{\mathrm{c}}\right) E_{0}\left(\varepsilon_{\mathrm{c}}-\widetilde{\varepsilon}_{\mathrm{c}}^{\mathrm{pl}}\right), \\
& \sigma_{\mathrm{t}}=\left(1-d_{\mathrm{t}}\right) E_{0}\left(\varepsilon_{\mathrm{t}}-\widetilde{\varepsilon}_{\mathrm{t}}^{\mathrm{pl}}\right),
\end{aligned}
$$

where $E_{0}$ is the initial elastic modulus of the concrete, $\varepsilon$ is the total strain, $\widetilde{\mathcal{E}}^{\mathrm{pl}}$ is the equivalent plastic strain, and $\sigma$ is the
TABLe 3: Element sizes in the mesh sensitivity study.

\begin{tabular}{lcc}
\hline Case no. & $\begin{array}{c}\text { Element sizes in the "O" region }(\mathrm{mm}) \\
\text { Concrete }\end{array}$ & $\begin{array}{c}\text { Reinforcement } \\
1\end{array}$ \\
\hline 1 & $150 \times 150 \times 150$ (10 layers) & 180 \\
3 & $200 \times 200 \times 187.5$ (8 layers) & 230 \\
4 & $250 \times 250 \times 250$ (6 layers) & 280 \\
5 & $300 \times 300 \times 300$ (5 layers) & 350 \\
\hline
\end{tabular}

stress. Subscripts $t$ and $c$ refer to tension and compression, respectively. In the current study, the uniaxial stress-strain curves for both tension and compression are taken from the Chinese Code for Design of Concrete Structures [25]. The damage evolution law proposed by Hao et al. [26] is adopted. The damage parameters are written as

$$
\begin{aligned}
& d_{\mathrm{c}}=1-e^{-\alpha_{\mathrm{c}}\left(\varepsilon_{\mathrm{c}}-\varepsilon_{\mathrm{c} 0}\right) / \varepsilon_{\mathrm{c} 0}}, \\
& d_{\mathrm{t}}=1-e^{-\alpha_{\mathrm{t}}\left(\varepsilon_{t}-\varepsilon_{\mathrm{t} 0}\right) / \varepsilon_{\mathrm{t} 0}},
\end{aligned}
$$

where $\alpha_{\mathrm{c}}$ and $\alpha_{\mathrm{t}}$ are damage parameters depending on material properties which are taken as 0.5 and $\varepsilon_{\mathrm{c} 0}$ and $\varepsilon_{\mathrm{t} 0}$ are compressive and tensile strains corresponding to peak compressive stress and tensile stress on the uniaxial stressstrain curve. Under cyclic loading conditions, the degradation of elastic modulus is described by a scalar stiffness degradation variable $d$, which also ranges from 0 (undamaged) to 1 (fully damaged). The effective elastic modulus $E$ is calculated by

$$
E=E_{0}(1-d)
$$

The scalar stiffness degradation variable $d$ is the combination of tensile and compressive damage parameters, defined by 


$$
1-d= \begin{cases}{\left[1-\left(1-w_{\mathrm{t}}\right) d_{\mathrm{c}}\left(1-d_{\mathrm{t}}\right)\right],} & \text { tension, } \\ \left(1-d_{\mathrm{c}}\right)\left[1-\left(1-w_{\mathrm{c}}\right) d_{\mathrm{t}}\right], & \text { compression, }\end{cases}
$$

where $w_{\mathrm{t}}$ and $w_{\mathrm{c}}$ are material properties that control the recovery of the tensile and compressive stiffness related to stress reversals. According to the experiments carried out by Ramtani et al. [27], tensile cracks are closed when load changes from tension to compression and the stiffness of the concrete is not affected by accumulated damage in tension. Therefore, $w_{\mathrm{c}}=1$ allows for full recovery of compressive stiffness when the load changes from tension to compression. $w_{\mathrm{t}}=0$ indicates no recovery when the load changes from compression to tension. The material parameters used to define the damaged plasticity model are listed in Table 4 .

The effect of the strain rate is incorporated by increasing the static strength by the dynamic increase factor (DIF). The values of DIF are 1.1 and 1.2 for tension and compression, respectively, according to CEB-FIP [28] considering the range of the strain rate in an aircraft impact.

For the steel reinforcement, the classical Johnson-Cook plastic model, as described in Section 2.1, was incorporated to consider the dependence of the yield strength on the strain and the strain rate. The constitutive parameters used to define the material according to Borvik et al. [29] are listed in Table 5.

2.3. Integral Crash Analysis of Boeing 767-200ER. Based on the above FE models of the airplane and containment building, the impact of the Boeing 767-200ER airplane crashing on the containment is simulated through the missile-target interaction method using ABAQUS/Explicit. The containment is fixed at the base. The aircraft is assumed to strike the containment normally at a height of $40 \mathrm{~m}$, which is approximately half of the total height. This condition is considered the most destructive case as reported by Sadique et al. [11] and Zhang et al. [13]. The initial velocity of the aircraft is assumed to be $150 \mathrm{~m} / \mathrm{s}$, which is used by Jeon et al. [30] for structures with relatively low altitude. The time increments range from $3 e-7 \mathrm{~s}$ to $7 e-7 \mathrm{~s}$. It has been demonstrated that further reduction in the time increment does not result in discrepancies in the calculated results.

\section{Validation of the Numerical Model}

3.1. Validation of the Aircraft Model. In order to validate the aircraft model and obtain the load of the impact, the crash analysis of Boeing 767-200ER on a rigid wall is carried out using both theoretical and numerical methods.

3.1.1. Calculation of Force-Time History of Boeing 767-200ER. First, the force-time history is calculated by the FE method. The target flat wall is modelled as a rigid body with all degrees of freedom fixed. The contacts between the aircraft to the rigid wall and the aircraft to itself are considered during the analysis. The contact forces between the wall and
TABLE 4: Material parameters of the damaged plasticity model for concrete.

\begin{tabular}{lc}
\hline Material parameters of the damaged plasticity model & Value \\
\hline Density $\left(\mathrm{kg} / \mathrm{m}^{3}\right)$ & 2500 \\
Modulus of elasticity, $E(\mathrm{GPa})$ & 33.5 \\
Tensile strength, $\sigma_{\mathrm{t}}(\mathrm{MPa})$ & 2.64 \\
Compressive strength, $\sigma_{\mathrm{c}}(\mathrm{MPa})$ & 29.6 \\
\hline
\end{tabular}

TABle 5: Material parameters of the Johnson-Cook model for the steel reinforcement.

\begin{tabular}{lc}
\hline Constitutive parameters of the steel reinforcement & $\begin{array}{c}\text { Parameter } \\
\text { value }\end{array}$ \\
\hline Young's modulus $(\mathrm{MPa})$ & $2.0 \times 10^{5}$ \\
Poisson's ratio & 0.3 \\
Density $\left(\mathrm{kg} / \mathrm{m}^{3}\right)$ & 7850 \\
$A(\mathrm{MPa})$ & 400 \\
$B(\mathrm{MPa})$ & 383 \\
$C$ & 0.0114 \\
$m$ & 0.94 \\
$n$ & 0.45 \\
$T_{\text {melt }}(\mathrm{K})$ & 1800 \\
\hline
\end{tabular}

the main parts of the airplane, i.e., the fuselage, the engine, and the wings, are obtained separately in the output to study their contributions to the total impact force. The time history outputs of impact forces are smoothed by a low-pass filter with a frequency of $100 \mathrm{~Hz}$.

The impact force of Boeing 767-200ER can also be theoretically predicted by the Riera function [4], which can be written as

$$
\begin{aligned}
F(t) & =M(x(t)) a(t)+V(t) \frac{\mathrm{d}}{\mathrm{d} t} M(x(t)) \\
& =P_{\mathrm{c}}(x(t))+\mu(x(t)) V(t)^{2},
\end{aligned}
$$

where $x(t)$ is the crushed length of the aircraft at time $t ; a(t)$ and $V(t)$ are acceleration and velocity of the uncrushed part of the aircraft at time $t$, respectively; $\mu(x)$ is the mass per unit length at location $x$; and $M(x(t))$ is the mass of the uncrushed part, calculated by

$$
M(x(t))=\int_{x(t)}^{L} \mu(x) \mathrm{d} x,
$$

where $L$ is the total length of the aircraft. $P_{\mathrm{c}}(x)$ is the static force required to crush the shell at location $x$, which does not affect the magnitude of the impact force significantly. $P_{c}(x)$ is taken as $10 \%$ of the total impact force $F(t)$ according to IAEA [31]. Based on the above equations and the kinematic relations between crushed length $x(t)$, velocity $V(t)$, and acceleration $a(t)$, the force-time history is obtained through numerical procedures.

In an ideal plastic impact assumed in both the theoretical and the current numerical method, the momentum and impulse are governed by the following equation:

$$
\int_{0}^{T} F(t) \mathrm{d} t=M_{0} V_{0}
$$


where $M_{0}$ and $V_{0}$ are the initial mass and velocity of the aircraft and $T$ is the total time of impact. The impulse of the numerical results at the end of impact can be checked by equation (10).

3.1.2. Force-Time History Results. Figures 4 and 5 show the force-time history and impulse curve results of Boeing 767200ER hitting on a flat rigid wall for WT and CT cases. The dashed lines represent theoretic values calculated by the Riera method, while the solid lines show the numerical results derived by FE models. The contributions of different parts of the plane to the total force are also shown in Figure 4. The impulse curves derived by the two methods shown in Figure 5 are similar. The difference of the impulse value at the end of the impact is within $2 \%$ error compared to the initial momentum of the aircraft, which has validated the numerical model using the principle of momentum in equation (10). The force-time history curves from two methods generally show good agreement in the overall trend. However, slight differences can still be observed in both magnitude and time distribution. The Riera method predicts a single peak of force during the crash of the wings in Figure 4(a). But in the numerical results, double peaks which are mainly related to the crash of wings can be observed in this time period. It can be seen from the velocity contour in Figure 6 that as the crushing force decelerates the main structures of the uncrushed part of the aircraft, the wing tips are hardly affected by the interaction force and keep moving with the initial velocity. Therefore, the wings are gradually deforming and the sweep angle of the wings is reducing. The relative displacement of the wing tips to the fuselage is almost $4 \mathrm{~m}$ when the wings crash onto the wall. As shown in Figure 6(a), an increased wing mass hits on the wall, which generates the second peak on the force history curve at about $0.175 \mathrm{~s}$. According to the theoretical prediction, the wings are supposed to impact on the wall until about $0.24 \mathrm{~s}$, and the impact force gradually reduces. But it can be seen from Figure 6(b) that the crush of the wings finishes at about $0.2 \mathrm{~s}$ because of the deformation of the wings, after which the interaction force of the wings diminishes. This can explain the abrupt decrease in the interaction force in Figure 4(a) around $0.2 \mathrm{~s}$. In this sense, the difference between the solid and dashed curves can be mainly attributed to the deformation of the uncrushed part which is not considered in the Riera method.

A comparison between Figures 4(a) and 4(b) indicates that the maximum interaction force is about $30 \%$ larger for the CT case. However, when focusing on the impact force related to the fuselage, the maximum force for the CT case is more than 3 times that of the WT case, indicating a much stronger impact in the fuselage region.

With the analysis and validation in this section, the FE model for the Boeing 767-200ER aircraft is regarded as reasonable and is used in the following missile-target interaction.

3.2. Validation of the Integral Analysis Model. In order to validate the modelling of the RC structure and the integral analysis method, a numerical simulation of the IRIS_2010 bending test [32] is carried out with the current modelling techniques. A quarter of the concrete slab and missile of the test are modelled, as shown in Figure 7. The supporting frame is sufficiently rigid so it is not modelled in detail. Out-of-plane restraint is applied on both front and rear faces along the edges to simulate the simple support condition. Spring elements are applied to model the compliance of the supporting back pipes. The constitutive models for the concrete, reinforcement, and missile are the same as those introduced in Section 2. The material constants corresponding to the experiment [33] are adopted. The stress-strain relation for concrete under compressive stress is defined according to test results [33]. The stress-crack opening relation recommended by Hordijk [34] is used to describe the tension behavior of the concrete. The missile impacts the concrete slab with a velocity of $110 \mathrm{~m} / \mathrm{s}$.

The deformation of the missile is shown in Figure 8. The missile is shortened by $935 \mathrm{~mm}$ if the folded part is taken into consideration and $1154 \mathrm{~mm}$ if it is neglected according to numerical analysis. The number of folds is 22 . The simulation results are in good agreement with the measured values in the experiment, which are $971 \mathrm{~mm}, 1156 \mathrm{~mm}$, and 22 , respectively. The calculated displacements and strain are compared to the experimentally measured data of the displacement sensors 1 and 4 and the strain gauge 2 on the front surface [32] in Figures 9 and 10. The maximum slab displacement and strain in the front surface match well with the experimental results.

\section{Results of Missile-Target Interaction Analysis}

4.1. Results of Mesh Convergence Analysis. The displacementtime histories of the node on the inner surface of the containment at the center of the impact region (point A in Figure 3) are plotted in Figure 11 for cases 1, 3, 4, and 5. For case 5, which gives 4 elements through wall thickness, the local deformation is underestimated by about $15 \%$. As the mesh is refined, the deformation results converge to a unique solution. For cases 1-3, the maximum error in deformation is less than 5\%. Therefore, the mesh with 6 elements through wall thickness provides satisfactory deformation results in an integrated analysis.

Figure 12 shows the strain contour of the models with various meshes. The strain is obviously dependent on mesh sizes. Since the strain gradient along the thickness direction is quite large, 8 layers of elements are required to describe the strong variation of stress and strain in the thickness. Otherwise, the strain on the outer surface is likely to be underestimated, as shown in Figures 12(c) to 12(e). The above results indicate that the mesh density widely used in previous studies in the literature may not be adequate to predict the response of the containment accurately. A mesh with element sizes no larger than $200 \mathrm{~mm}$ which gives at least 8 elements through wall thickness is recommended at the impact region for a missile-target interaction analysis with similar configurations.

4.2. Impact Phenomenon. The impact phenomenon and damage evolution of the WT case are described in this section. 


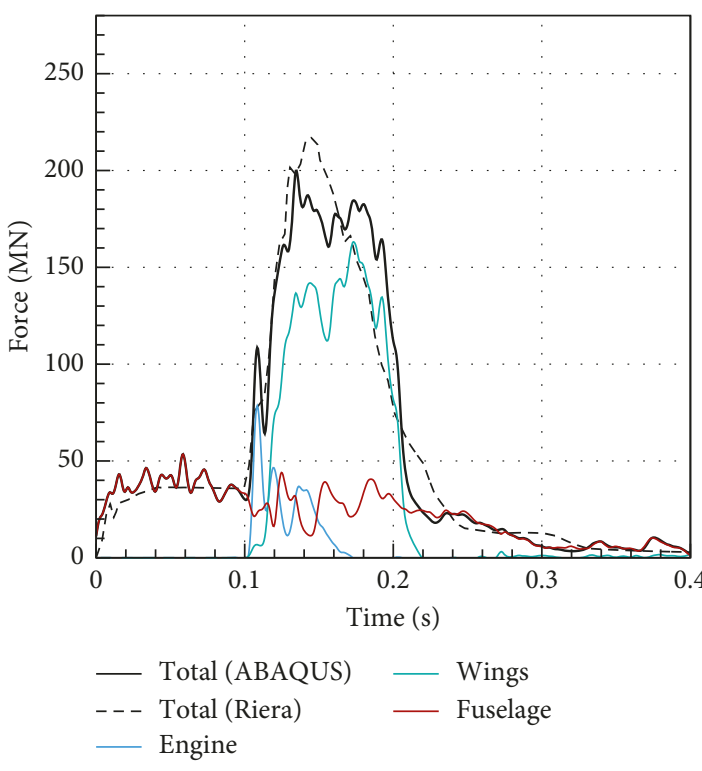

(a)

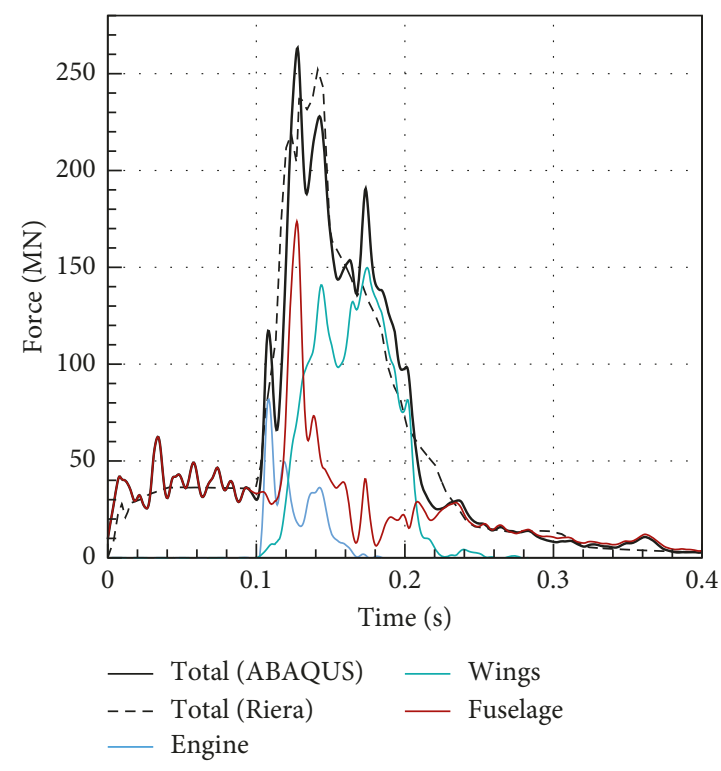

(b)

Figure 4: Force-time history results of Boeing 767-200ER. (a) WT case. (b) CT case.

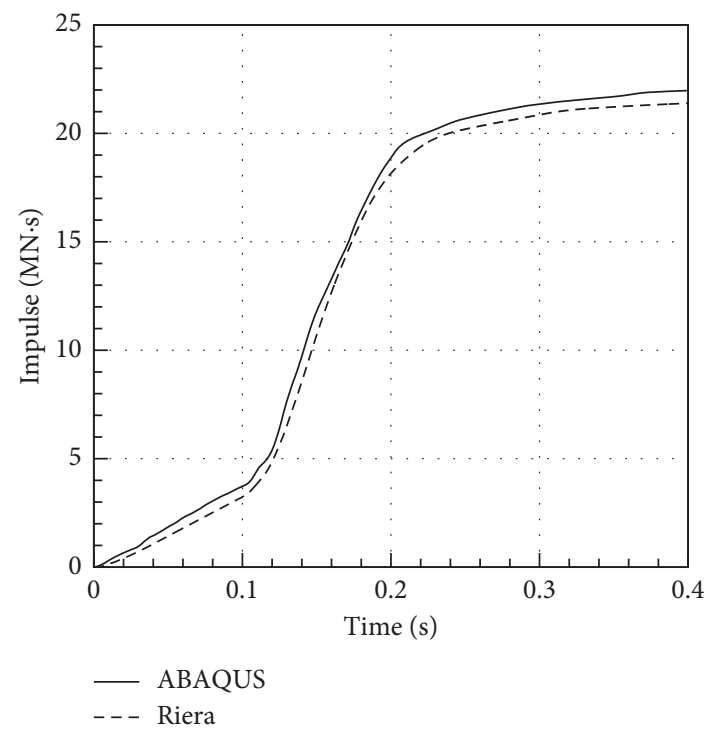

(a)

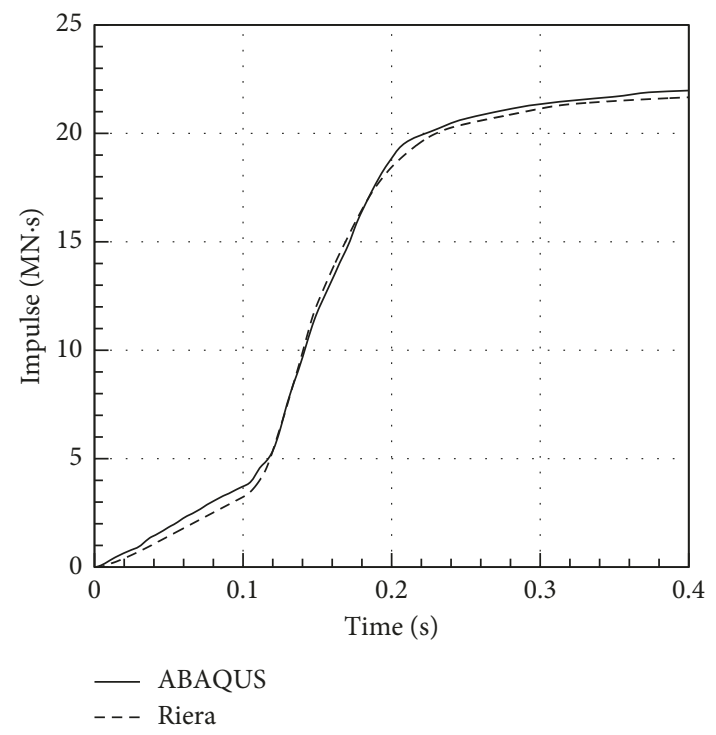

(b)

FIgURE 5: Impulse-time history results of Boeing 767-200ER. (a) WT case. (b) CT case.

As shown in Figure 11, the deformation slightly increases during the impact of the fuselage before $0.1 \mathrm{~s}$. After the wings begin to crash on the containment at about $0.11 \mathrm{~s}$, the deformation significantly increases. The deformation in the containment reaches the maximum value at about $0.25 \mathrm{~s}$ when the impact of the wings is finished. After that, the velocity of the aircraft as well as the impact force drops significantly and the elastic deformation gradually recovers, while the plastic deformation remains in the concrete.

Figure 13 shows the snapshots of the impact and the contours of the stiffness degradation variable $d$, defined by equations (6) and (7), on the containment at $0.10 \mathrm{~s}, 0.15 \mathrm{~s}$, $0.20 \mathrm{~s}, 0.25 \mathrm{~s}, 0.27 \mathrm{~s}, 0.30 \mathrm{~s}$, and $0.40 \mathrm{~s}$. The impact of fuselage during $0 \mathrm{~s} \sim 0.1 \mathrm{~s}$ only causes moderate damage on the containment (see Figure 13(a)). Once the wings crash on the containment, the damage grows significantly. In the impact region, the stress is dominated by the compression load. At a distance to the impact region, the stress is dominated by the bending load. Large tensile stress is generated on the outer surface of the containment around the impact region, and tensile damage can be observed. Figure 14 shows the time history of the circumferential stress at a typical point on the 


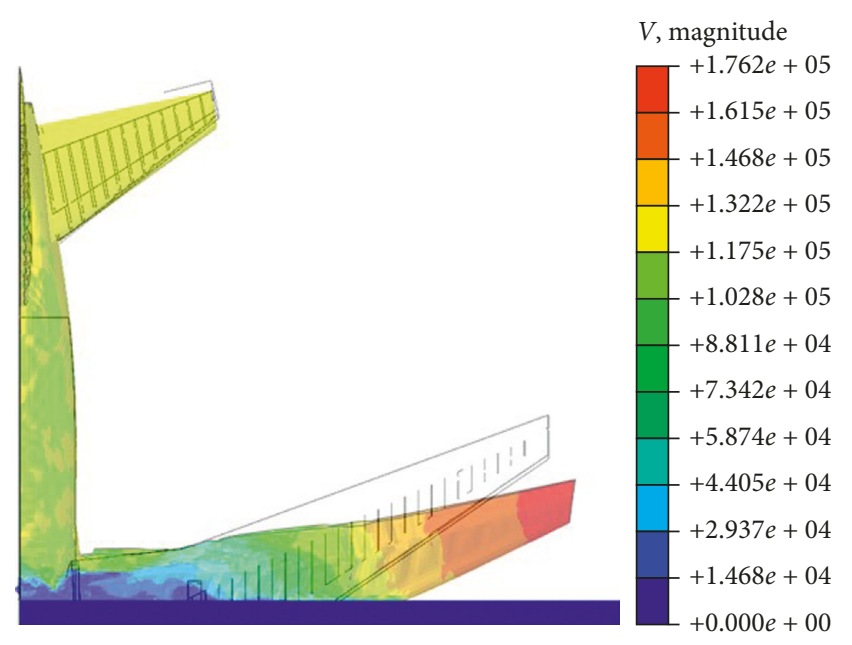

(a)

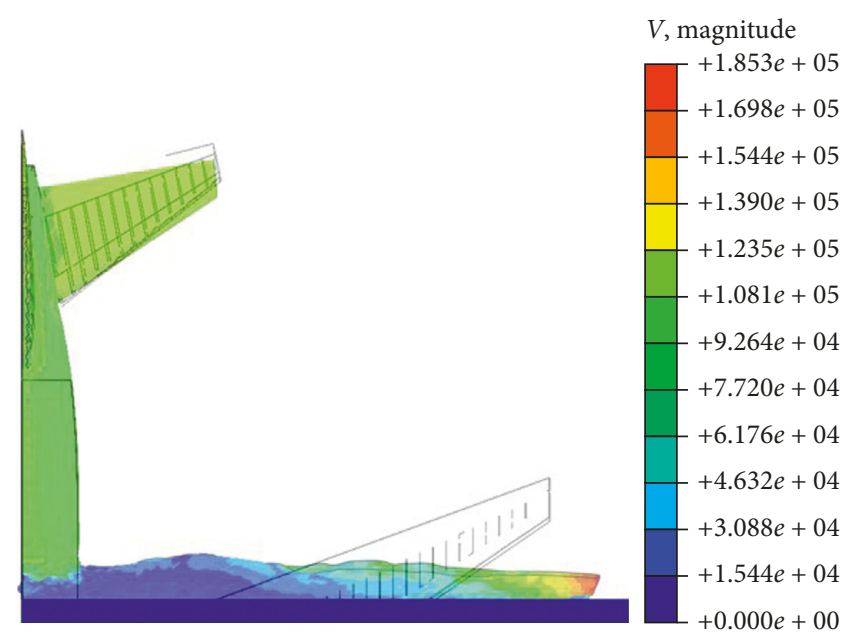

(b)

Figure 6: Snapshots of Boeing 767-200ER hitting on a rigid wall. (a) $0.175 \mathrm{~s}$. (b) $0.200 \mathrm{~s}$.

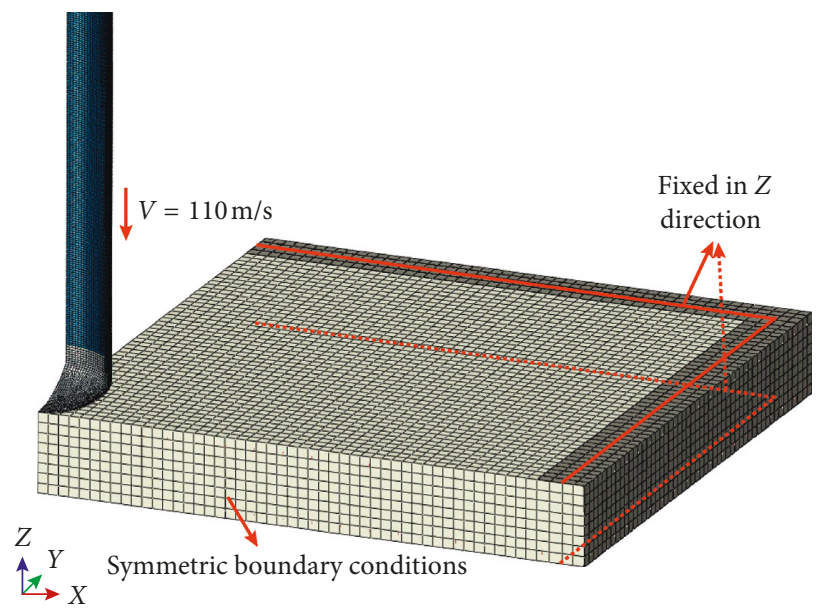

Figure 7: Finite element model of the impact simulation.

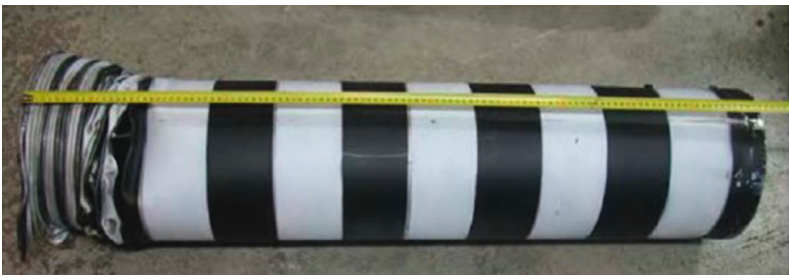

(a)

Figure 8: Deformation of the missile. (a) Experiment. (b) Numerical Simulation.

outer surface of the containment (identified as point B in Figure 13), which is away from the impact region of the fuselage. During the impact of the fuselage, tensile stress is observed at point $\mathrm{B}$. When the wings begin to crash, point $\mathrm{B}$ is located in the impact region. The stress state turns from tension to compression, making the open cracks to close. Stiffness recovery (i.e., reduction in $d$ ) can be observed in these regions. Although the concrete in these regions can no

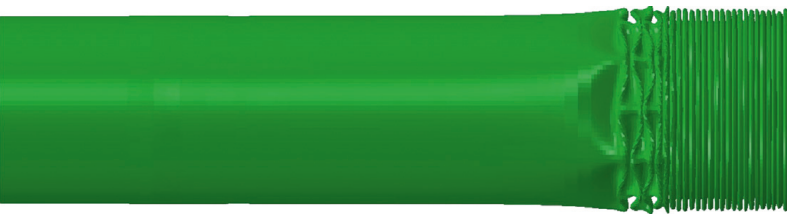

(b) longer sustain tensile loads, the resistant capacity still remains when the load is compressive. Besides the damage around the impact area, tensile damage is also observed at the bottom of the containments, which is related to the bending moment caused by the aircraft impact force. It can be seen from Figure 13 that the outer surface suffers from most severe tensile cracking during $0.2 \mathrm{~s}$ to $0.25 \mathrm{~s}$. After $0.27 \mathrm{~s}$, as the impact load decreases, the elastic restoring force 


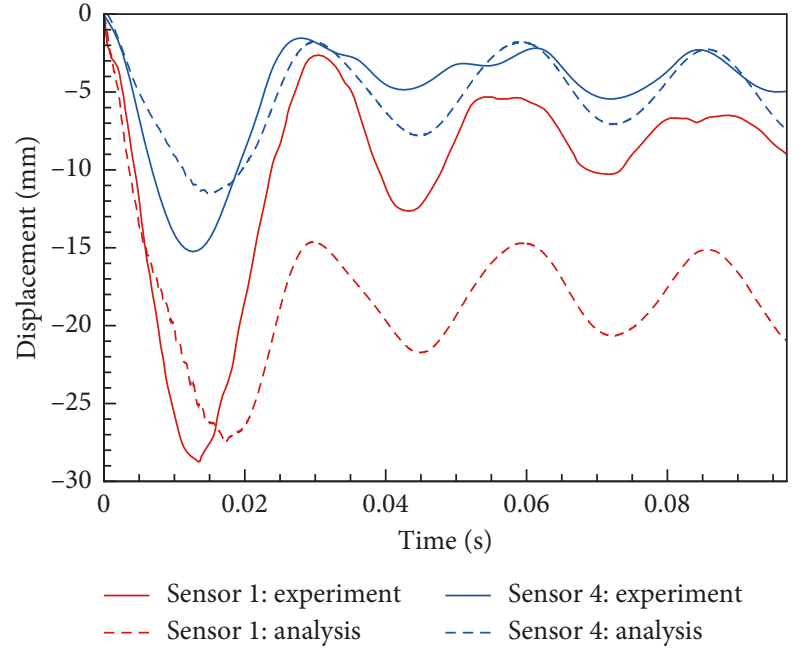

FIgURE 9: Displacement at sensors 1 and 4.

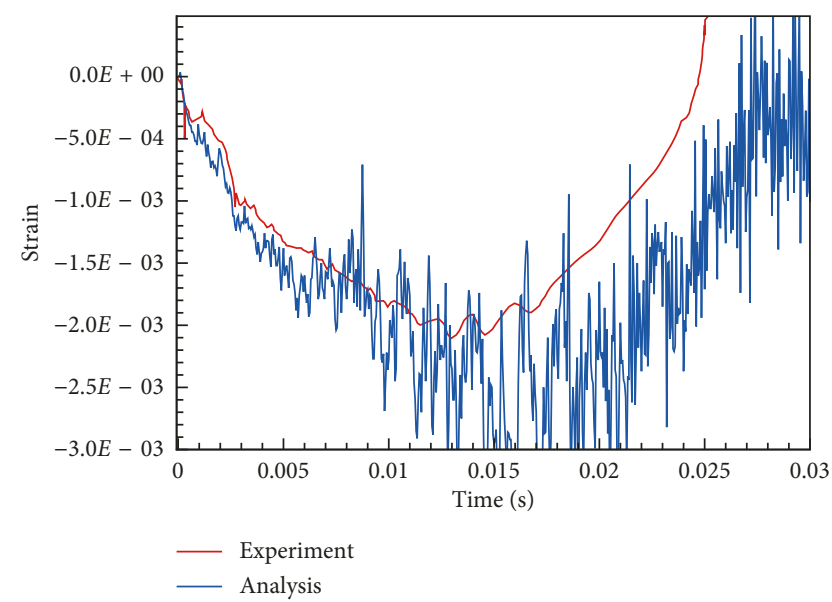

FIGURE 10: Strain at the front surface of the slab (strain gauge 2).

of the reinforcement generates a compression load on the cracks, which also leads to crack closure and the decrease of deformation of the containment. At the end of the crash, a large number of open cracks are closed and stiffness is largely recovered.

4.3. Effects of Fuel Distribution. The analysis results of two scenarios with different fuel distribution, i.e., WT and CT cases, are compared in this section. The displacement-time histories of point A (see Figure 3) on the containment for the two cases are shown in Figure 15. The equivalent plastic strain distribution on the inner surface of the containment along a circumferential path through point $\mathrm{A}$ at $0.25 \mathrm{~s}$ for the two cases is shown in Figure 16. The $X$-axis is the distance to point A. Although the total mass of the two aircraft models is the same and the maximum magnitude of force-time history differs by only about $30 \%$, the damage results are significantly different. The maximum displacement and strain of the concrete in the CT case are, respectively, about 2.1 and 10 times larger than those in the WT case.

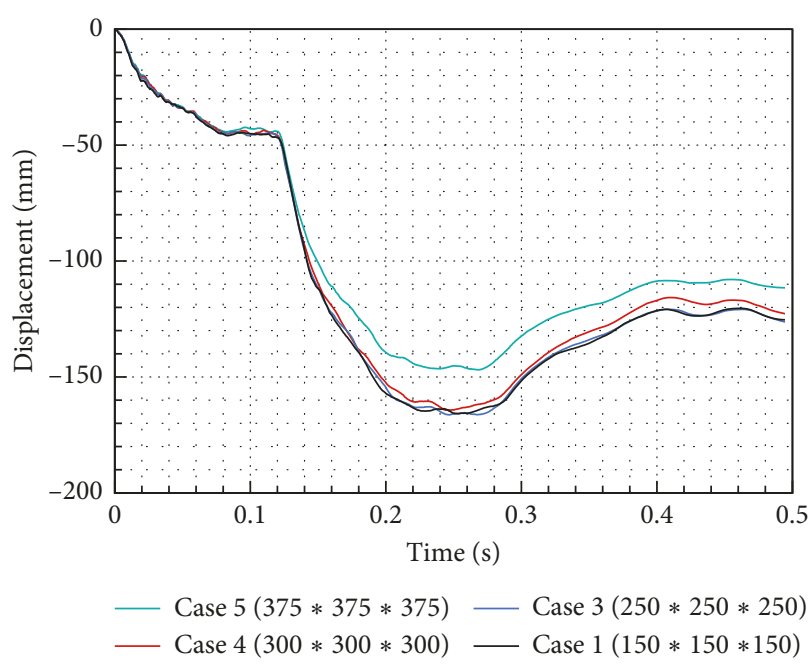

FIGURE 11: Displacement of the containment in the impact region for various element sizes.

The above results indicate that the spanwise mass distribution is critical in an aircraft impact analysis. If the mass is highly concentrated, severe local damage may occur in the impact region. On the contrary, if the mass is evenly distributed in the transverse direction, the increased impact area reduces the peak value of impact forces which helps to raise the resistant capacity. In a classic decoupled analysis, the spanwise mass distribution is not incorporated. Therefore, the method is not able to provide corresponding results for airplanes with various spanwise mass distribution. This may lead to considerable inaccuracy in prediction of damage. For this reason, a decoupled analysis with separated impact forces of components (i.e., fuselage, engine, and wings) applied as pressure loads on their projected area may help to increase accuracy. The application of an integral analysis is the most recommended way to fully incorporate the effect of mass distribution in the transverse direction in the safety assessment of the aircraft impact.

4.4. Damage Evaluation of the Containment. The resistant capacity of the containment building against crash of the airplane for both the WT case and the CT case is evaluated in this section according to the numerical results. The acceptance criteria for design extension event 1 (DEE1) defined by IAEA [31] are applied to evaluate the damage on the containment. In DEE1, local inelastic deformation and damage in the structure are accepted as long as the basic safety function of the containment is ensured. The failure criteria in DEE1 are that the compressive principal strain is less than 0.005 for concrete and the tensile strain is less than 0.05 for the steel reinforcement. Tensile cracking of the concrete is acceptable as long as the tensile forces are transferred to the reinforcement and the strain limit for the reinforcement is not exceeded. Besides, the 0.005 limit for the shear strain in the concrete required by NRC [1] is also applied to assess the integrity of the containment.

Figure 17 shows the compressive strain, shear strain, and compressive damage in the concrete as well as the tensile 


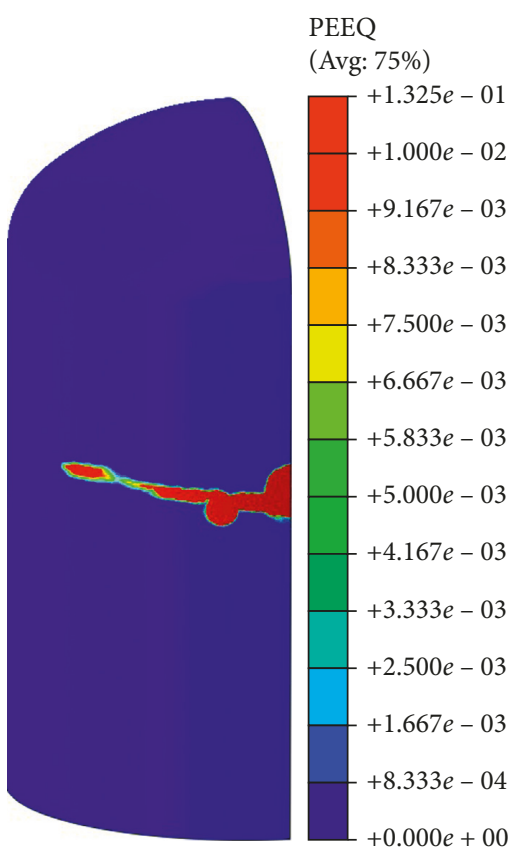

(a)

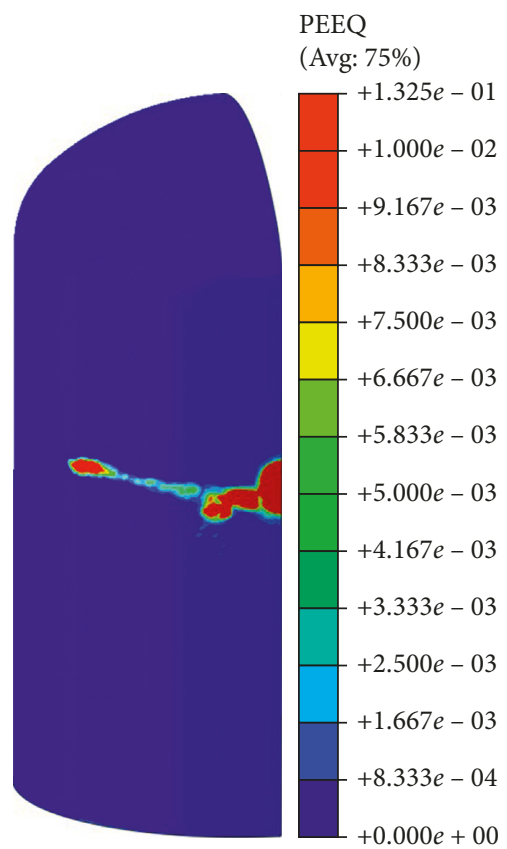

(c)

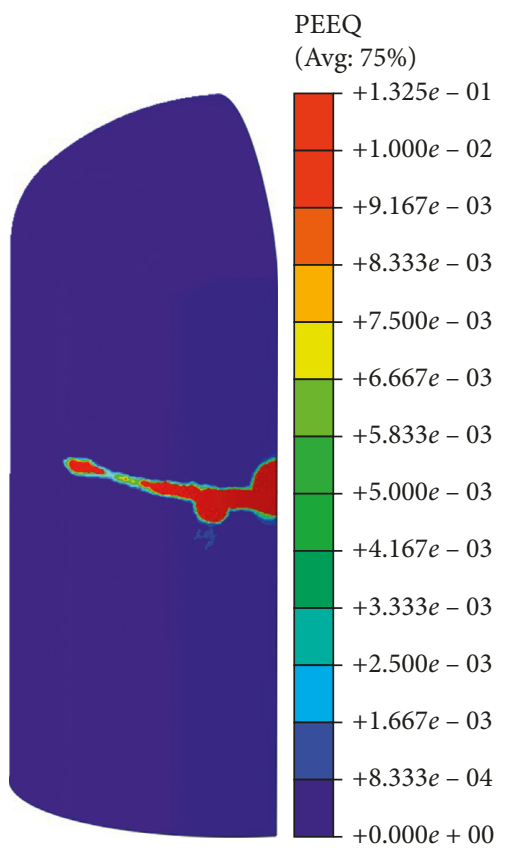

(b)

PEEQ

(Avg: $75 \%$ )

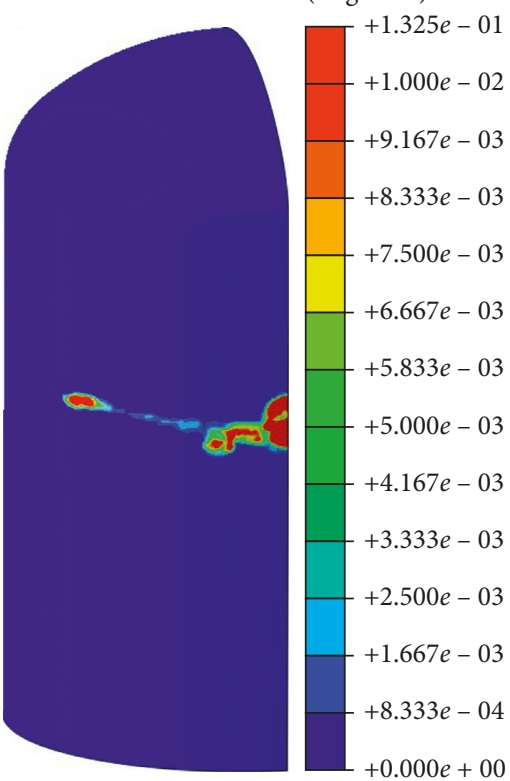

(d)

Figure 12: Continued. 


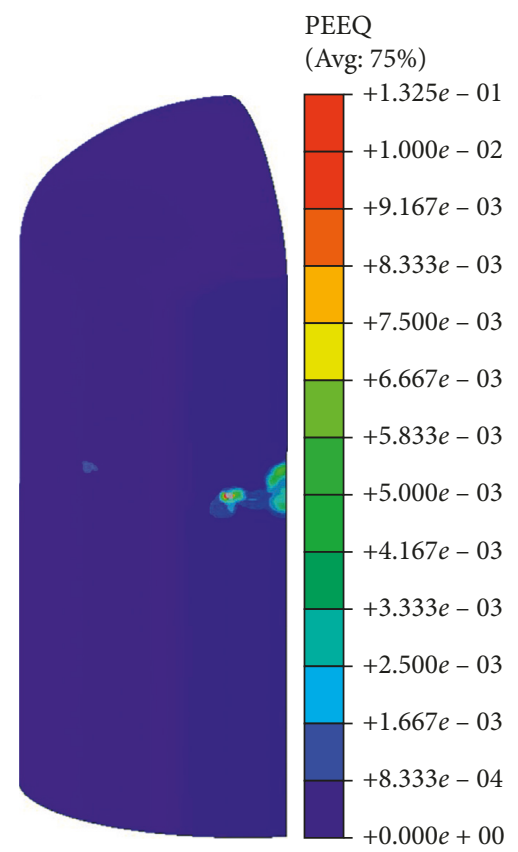

(e)

Figure 12: Strain contours of the containment for various element sizes (0.25 s). (a) Case 1. (b) Case 2. (c) Case 3. (d) Case 4 . (e) Case 5.

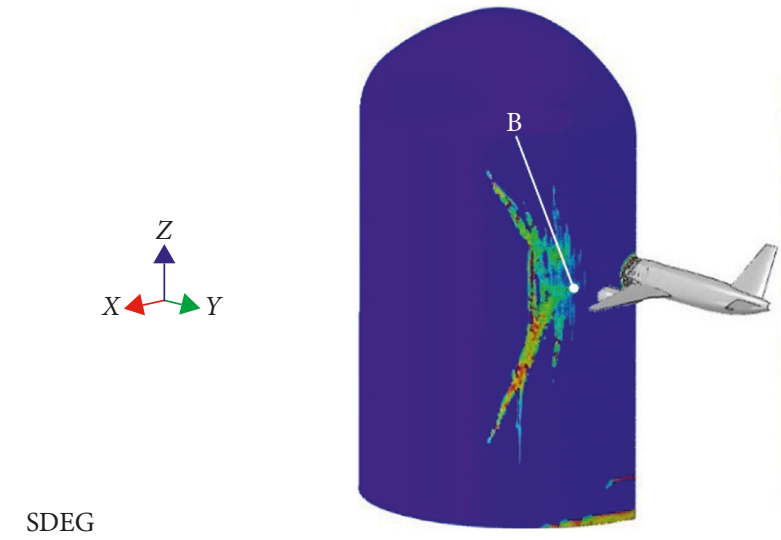

(Avg: $75 \%)$

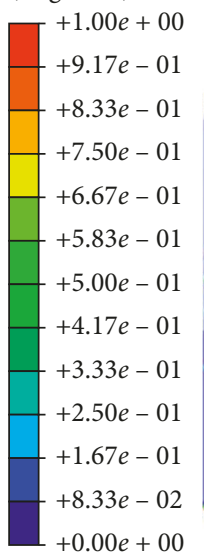

(a)

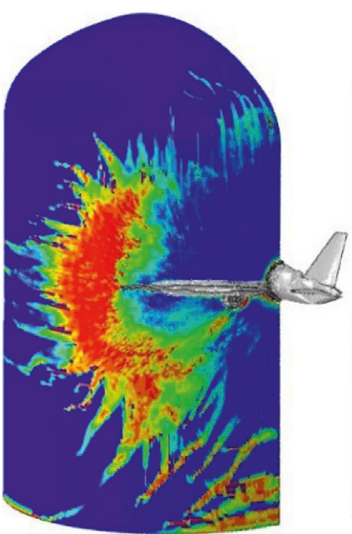

(d)

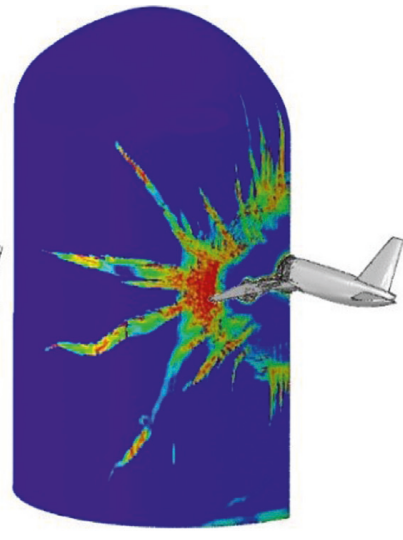

(b)

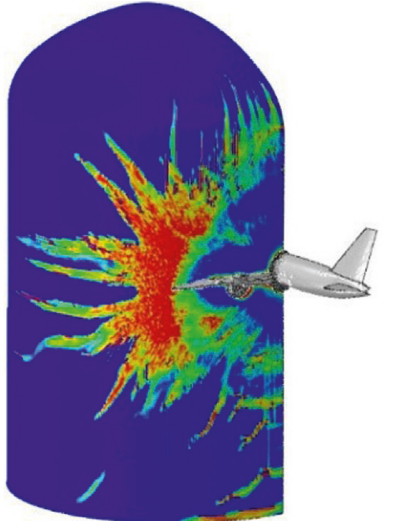

(c)

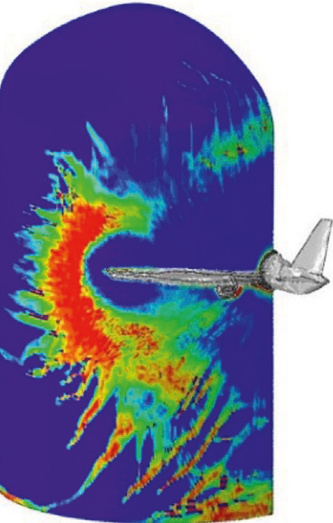

(e)

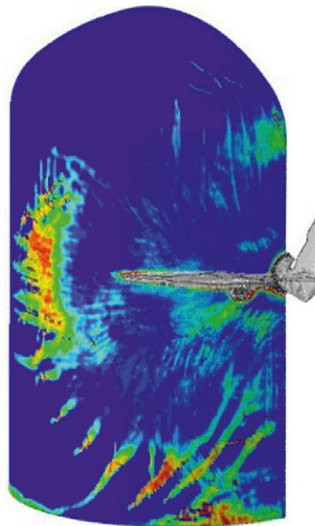

(f)

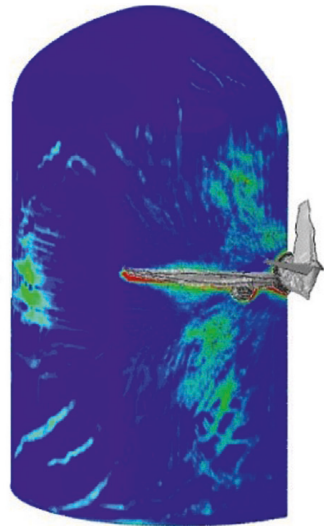

(g)

FIGURE 13: Snapshot from analysis of Boeing 767-200ER crash on the containment (wing tank case). (a) 0.10 s. (b) 0.15 s. (c) 0.20 s. (d) 0.25 s. (e) $0.27 \mathrm{~s}$. (f) $0.30 \mathrm{~s}$. (g) $0.40 \mathrm{~s}$. 


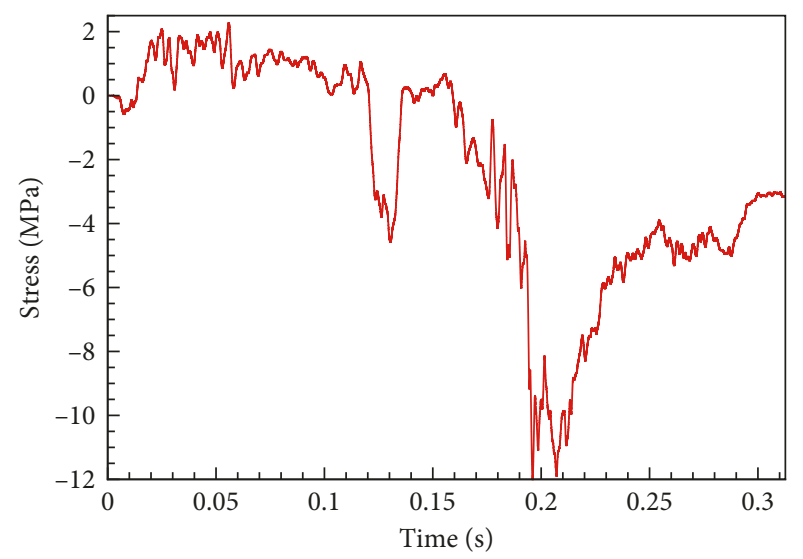

Figure 14: Circumferential stress-time history of point B (wing tank case).

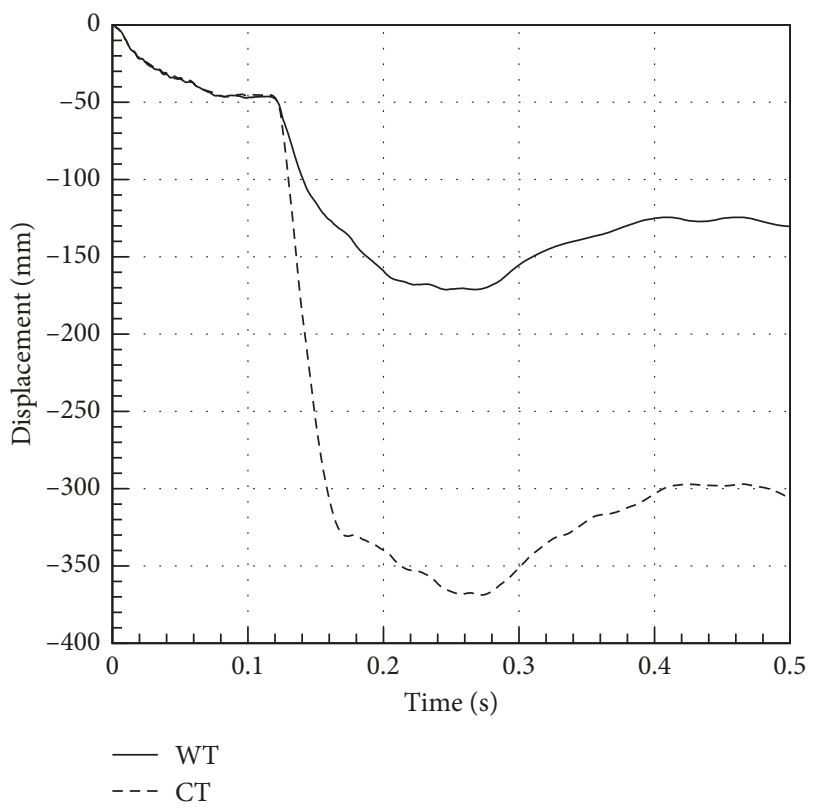

FIgURE 15: Displacement of the containment in the impact region with different fuel distribution.

strain in the bending reinforcement at $0.25 \mathrm{~s}$, corresponding to the timepoint of maximum deformation for the WT case. The outer face of the concrete which is in direct contact with the airplane suffers the most serious damage during the impact. The shear strain exceeds the limit (shown by the gray color in Figure 17(b)), and the compressive damage is close to 1 in this area. Outside this local region, the compressive damage is much less than 1 . The damaged area on the outer surface is about 1.3 times the projected area of the airplane. The maximum thickness of the concrete that suffers from compressive damage in the impact regions of the fuselage and the engine is about $550 \mathrm{~mm}$ and $410 \mathrm{~mm}$, respectively. On the inner face of the concrete, the shear strain is slightly greater than the limit in the impact area. However, complete shear failure through the wall is not observed. Therefore, shear capacity still remains. The tensile strain in the reinforcements, shown in Figure 17(d), is much less than the

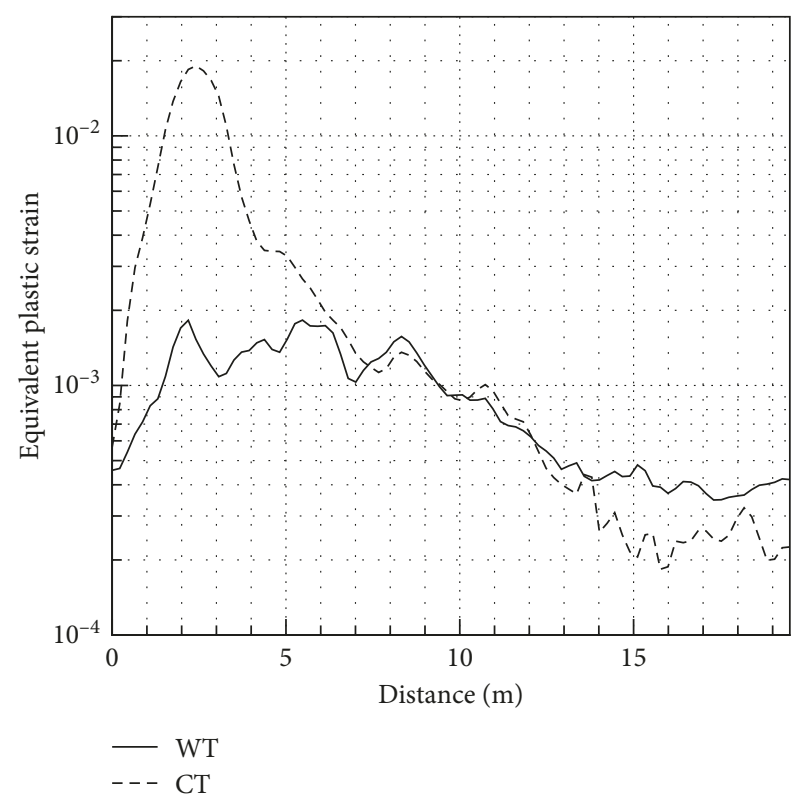

FIGURE 16: Equivalent plastic strain distribution on the inner surface of the containment along a circumferential path through point A (Figure 3) at $0.25 \mathrm{~s}$.

limit. Therefore, the tensile cracking in the concrete is acceptable. In this scenario, the impact results in limited local failure without perforations. Since the bearing capacity of the reinforcement is ensured and the deformation of the containment is limited, neither collapse nor overturning is observed in the structure. The overall stability of the containment is maintained.

The strain and damage at $0.25 \mathrm{~s}$ for the CT case are shown in Figure 18. A comparison between Figures 17 and 18 indicates that the fuel distribution has a strong effect on the damage distribution. In the impact region of the fuselage, the damage is much more severe in the CT case, while in the impact region of the wings, the influence of the crash for the CT case is relatively small. As shown in Figures 18(a) and 18(b), both the compressive strain and shear strain exceed the limit values throughout the wall thickness (shown by the dark gray color in Figure 18(a) and the gray color in Figure 18(b)). Although the concrete is severely damaged, the tensile strain in the reinforcement is basically within the limit value (see Figure 18(d)). Therefore, the overall stability is ensured in this case.

\section{Conclusion}

In the present study, an integral numerical analysis of impact of a commercial airplane Boeing 767-200ER on a reinforced containment building of a nuclear power plant is carried out. The force-time history of the airplane obtained by numerical analysis is in good agreement with the Riera function. The slight difference in the two results is due to the self-deformation of the airplane which is not incorporated in the Riera method. The integral analysis model is validated by simulating the IRIS_2010 experiment. A mesh sensitivity study of the containment model suggests that, in an integral 

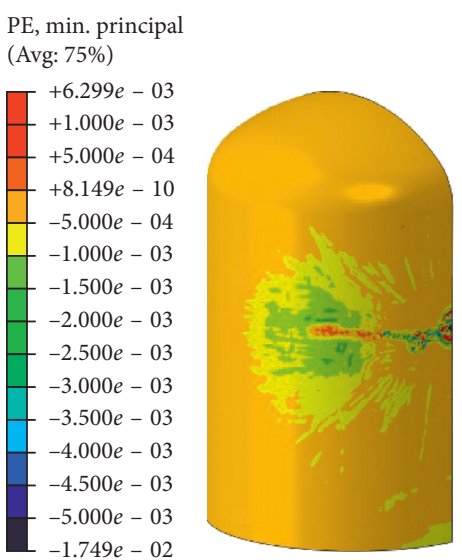

DAMAGEC (Avg: $75 \%$ )
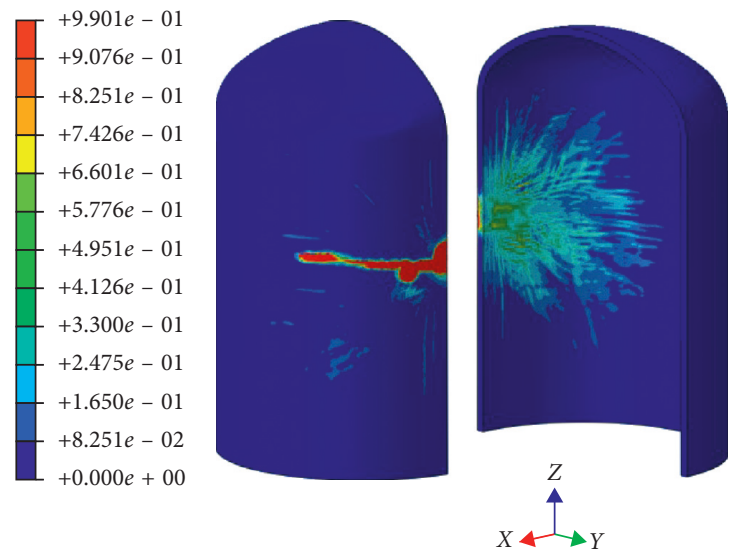

(c)
Shear strain

(Avg: 75\%)
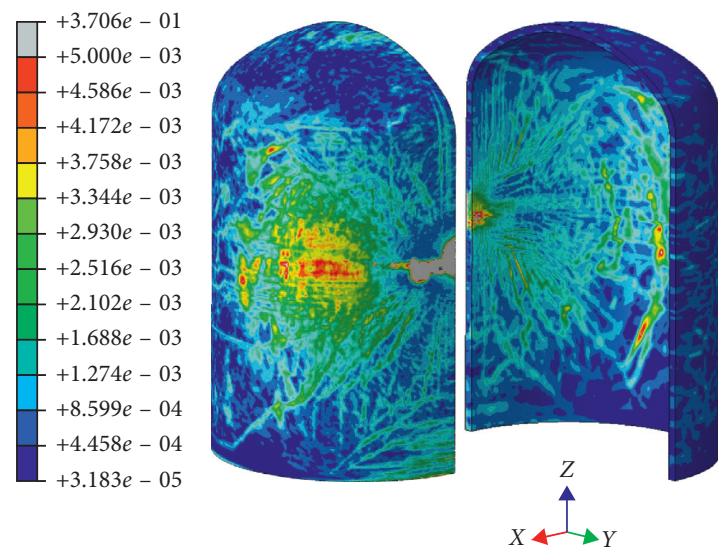

(b)

LE, max. principal SNEG (fraction $=-1.0)$ (Avg: $75 \%$ )
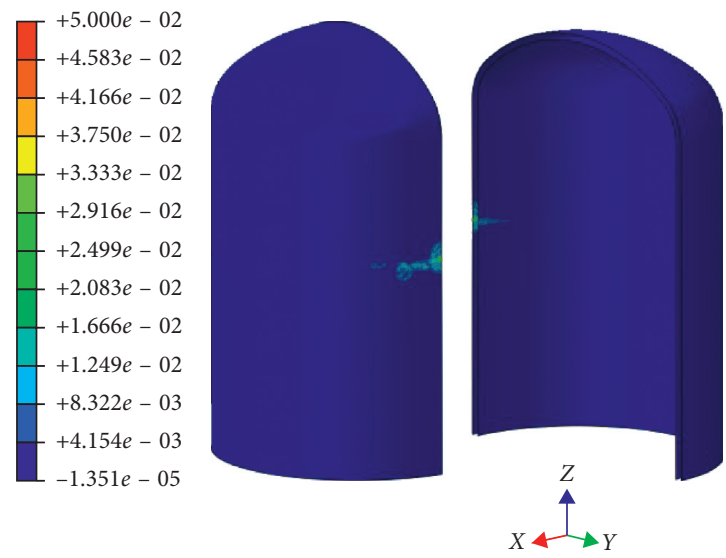

(d)

FIgURE 17: Numerical results of Boeing 767-200ER crash on the containment (WT case, 0.25 s). (a) Compressive strain in the concrete. (b) Shear strain in the concrete. (c) Compressive damage in the concrete. (d) Tensile strain in the reinforcement.
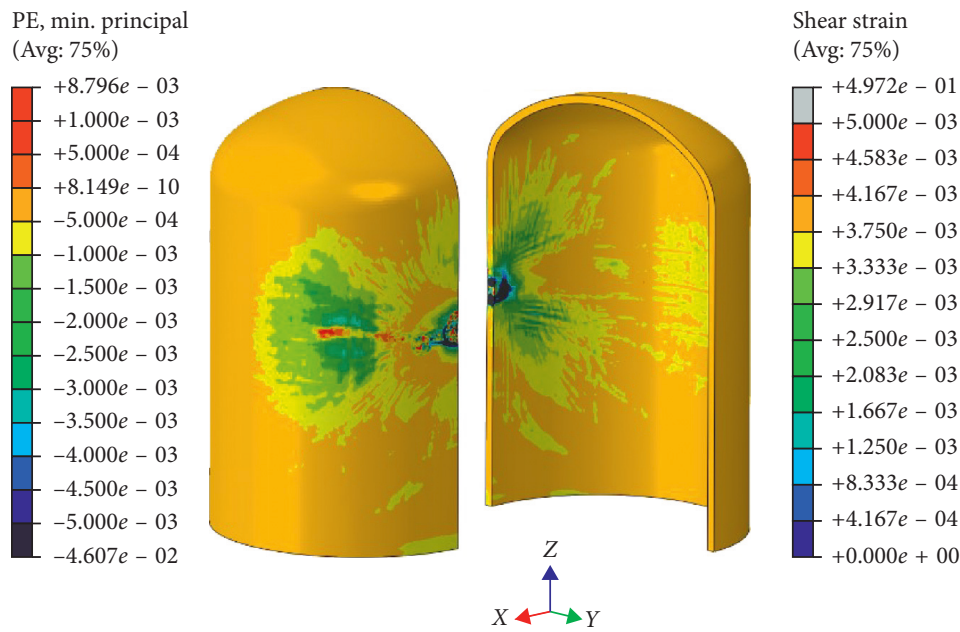

(a)
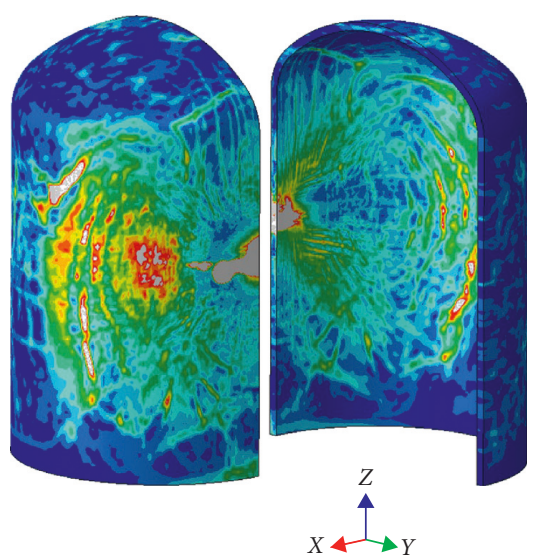

(b)

FIgURE 18: Continued. 

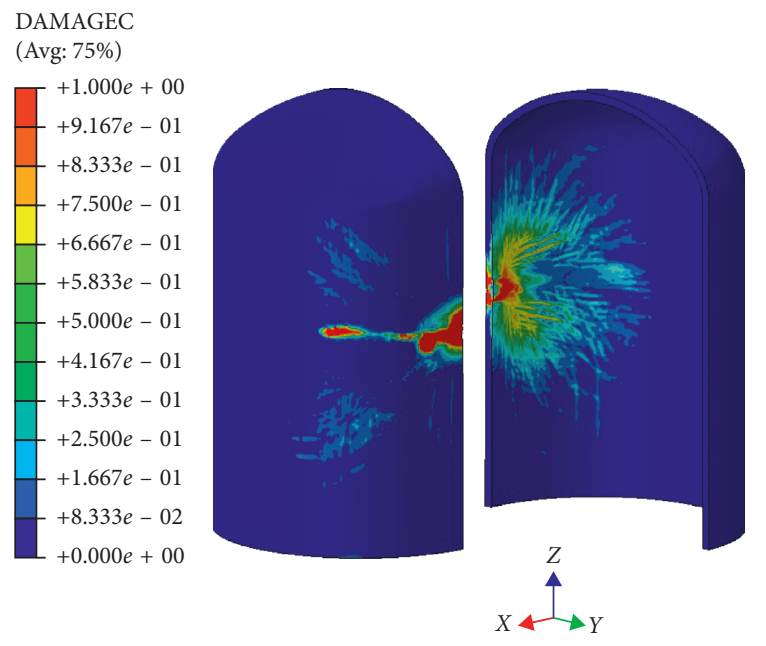

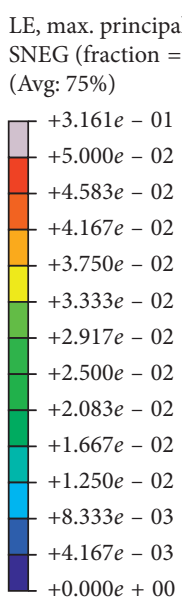

(c)
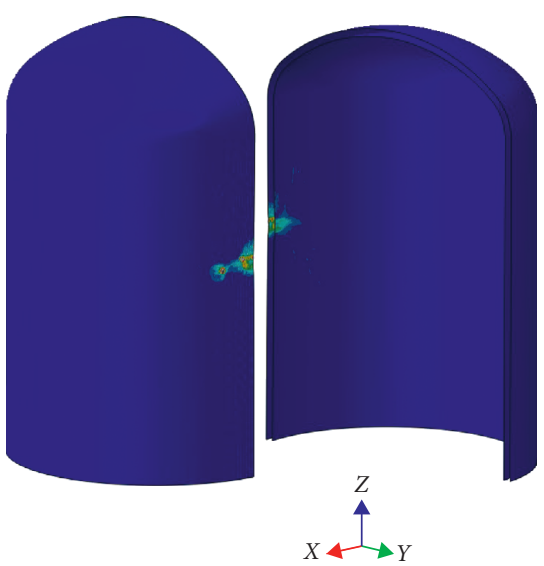

(d)

FIGURE 18: Numerical results of Boeing 767-200ER crash on the containment (CT case, $0.25 \mathrm{~s}$ ). (a) Compressive strain in the concrete. (b) Shear strain in the concrete. (c) Compressive damage in the concrete. (d) Tensile strain in the reinforcement.

analysis, a mesh that gives 8 elements through wall thickness is essential to provide satisfactory results.

The validated model is used to study the impact phenomenon. The evolution of the damage on the containment is shown by the numerical results. Tensile damage is observed around the impact area and the fixed base of the containment during the impact. However, the crack opening is closed as the load changes from tension to compression at the end of the impact.

The impact analyses of two plane models with the same total weight but different fuel distribution are carried out. Obvious differences in the displacement and damage are observed in the two cases. In the WT case, the containment only suffers from limited local damage, while in the CT case, the concrete fails though the wall in the impact region. The result shows that the mass distribution in the transverse direction is a critical parameter in an aircraft impact. An integral analysis is able to incorporate this factor and therefore provides more accurate results in the safety assessment of an aircraft impact than a classic load-time function analysis.

\section{Data Availability}

The data used to support the findings of this study are available from the corresponding author upon request.

\section{Conflicts of Interest}

The authors declare that they have no conflicts of interest.

\section{Acknowledgments}

Financial support from the National S\&T Major Project (Grant No. 2018ZX06902016) is gratefully acknowledged. The authors wish to express their sincere gratitude to Professor Song Cen and Ms. Li Lin of the School of
Aerospace Engineering in Tsinghua University for their contribution in aircraft modelling and their generous help.

\section{References}

[1] NEI07-13, Methodology for Performing Aircraft Impact Assessments for New Plant Designs, NEI07-13, Washington, DC, USA, 2011.

[2] IAEA, Safety Standard Series: External Events Excluding Earthquakes in the Design of Nuclear Power Plants. Safety Guide No. NS-G-1.5, IAEA, Vienna, Austria, 2003.

[3] H. Jiang and M. G. Chorzepa, "Aircraft impact analysis of nuclear safety-related concrete structures: a review," Engineering Failure Analysis, vol. 46, pp. 118-133, 2014.

[4] J. D. Riera, "On the stress analysis of structures subjected to aircraft impact forces," Nuclear Engineering and Design, vol. 8, no. 4, pp. 415-426, 1968.

[5] A. Siefert and F. O. Henkel, "Nonlinear analysis of commercial aircraft impact on a reactor building-comparison between integral and decoupled crash simulation," Nuclear Engineering and Design, vol. 269, pp. 130-135, 2014.

[6] K. Lee, S. E. Han, and J.-W. Hong, "Analysis of impact of large commercial aircraft on a prestressed containment building," Nuclear Engineering and Design, vol. 265, pp. 431-449, 2013.

[7] D.-K. Thai and S.-E. Kim, "Safety assessment of a nuclear power plant building subjected to an aircraft crash," Nuclear Engineering and Design, vol. 293, pp. 38-52, 2015.

[8] T. Sugano, H. Tsubota, Y. Kasai et al., "Full-scale aircraft impact test for evaluation of impact force," Nuclear Engineering and Design, vol. 140, no. 3, pp. 373-385, 1993.

[9] H. Abbas, D. K. Paul, P. N. Godbole, and G. C. Nayak, "Aircraft crash upon outer containment of nuclear power plant," Nuclear Engineering and Design, vol. 160, no. 1-2, pp. 13-50, 1996.

[10] R. L. Frano and G. Forasassi, "Preliminary evaluation of aircraft impact on a near term nuclear power plant," Nuclear Engineering and Design, vol. 241, no. 12, pp. 5245-5250, 2011.

[11] M. R. Sadique, M. A. Iqbal, and P. Bhargava, "Nuclear containment structure subjected to commercial and fighter 
aircraft crash," Nuclear Engineering and Design, vol. 260, pp. 30-46, 2013.

[12] M. A. Iqbal, M. R. Sadique, P. Bhargava, and N. M. Bhandari, "Damage assessment of nuclear containment against aircraft crash," Nuclear Engineering and Design, vol. 278, pp. 586-600, 2014.

[13] T. Zhang, H. Wu, Q. Fang, and T. Huang, "Numerical simulations of nuclear power plant containment subjected to aircraft impact," Nuclear Engineering and Design, vol. 320, pp. 207-221, 2017.

[14] M. Kostov, F. O. Henkel, and A. Andonov, "Safety assessment of A92 reactor building for large commercial aircraft crash," Nuclear Engineering and Design, vol. 269, pp. 262-267, 2014.

[15] T. Zhang, H. Wu, Q. Fang, and Z. M. Gong, "Influences of nuclear containment radius on the aircraft impact force based on the Riera function," Nuclear Engineering and Design, vol. 293, pp. 196-204, 2015.

[16] R. Y. Mei, J. B. Liu, G. Lin, and X. Y. Zhu, "Dynamic assessment of the seismic isolation influence for various aircraft impact loads on the CPR1000 containment," Nuclear Engineering and Technology, vol. 50, pp. 1387-1401, 2018.

[17] S. S. Shin, D. Hahm, and T. Park, "Shock vibration and damage responses of primary auxiliary buildings from aircraft impact," Nuclear Engineering and Design, vol. 310, pp. 57-68, 2016.

[18] ABAQUS (Software), Documentation of Version 2016, ABAQUS Inc., Palo Alto, CA, USA, 2016, http://www.abaqus. com.

[19] Boeing Commercial Airplanes, 767 Airplane Characteristics for Airport Planning, Boeing Commercial Airplanes, Seattle, WA, USA, 2005.

[20] L. Lin, X. Z. Lu, P. F. Han, S. Cen, and J. B. Liu, “Analysis of impact force of large commercial aircraft on rigid wall and nuclear power plant containment," Journal of Vibration and Shock, vol. 34, pp. 158-163, 2015.

[21] D.-K. Thai and S.-E. Kim, "Fluid effect of the water-filled missile on impact force," International Journal of Impact Engineering, vol. 90, pp. 95-105, 2016.

[22] G. R. Johnson and W. H. Cook, "A constitutive model and data for metals subjected to large strains, high strain rates and high temperatures," in Proceeding of the Seventh International Symposium on Ballistics, The Hague, The Netherlands, April 1983.

[23] G. R. Johnson and W. H. Cook, "Fracture characteristics of three metals subjected to various strains, strain rates, temperatures and pressures," Engineering Fracture Mechanics, vol. 21, no. 1, pp. 31-48, 1985.

[24] M. R. Karim and M. S. Fatt, "Impact of the boeing 767 aircraft into the world trade center," Journal of Engineering $\mathrm{Me}$ chanics, vol. 131, no. 10, pp. 1066-1072, 2005.

[25] China Architecture \& Building Press, GB50010-2010, Chinese Code for Design of Concrete Structures, China Architecture \& Building Press, Beijing, China, 2011.

[26] Y. Hao, H. Hao, and X. H. Zhang, "Numerical analysis of concrete material properties at high strain rate under direct tension," International Journal of Impact Engineering, vol. 39, no. 1, pp. 51-62, 2012.

[27] S. Ramtani, Y. Berthaud, and J. Mazars, "Orthotropic behavior of concrete with directional aspects: modelling and experiments," Nuclear Engineering and Design, vol. 133, no. 1, pp. 97-111, 1992.

[28] International Federation for Structural Concrete, CEB-FIP Model Code, International Federation for Structural Concrete, Lausanne, Switzerland, 2010.
[29] T. Borvik, O. S. Hopperstad, T. Berstad, and M. Langseth, "Perforation of $12 \mathrm{~mm}$ thick steel plates by $20 \mathrm{~mm}$ diameter projectiles with flat, hemispherical and conical noses-Part II: numerical simulations," International Journal of Impact Engineering, vol. 27, pp. 37-64, 2002.

[30] S.-J. Jeon, B.-M. Jin, and Y.-J. Kim, "Assessment of the fire resistance of a nuclear power plant subjected to a large commercial aircraft crash," Nuclear Engineering and Design, vol. 247, pp. 11-22, 2012.

[31] IAEA, "Safety aspects of nuclear power plants in human induced external events: assessment of structures," IAEA safety report series No. 87, IAEA, Vienna, Austria, 2018.

[32] A. Vepsa, A. Saarenheimo, F. Tarallo, J.-M. Rambach, and N. Orbovic, IRIS_2010-Part II: Experimental data, Vol. 21, SMiRT, New Delhi, India, 2011.

[33] NEA/CSNI, "Improving robustness assessment methodologies for structures impacted by missiles (IRIS_2010), final report," Tech. Rep. NEA/CSNI/R(2014)5, NEA/CSNI, Paris, France 2014.

[34] D. A. Hordijk, "Tensile and tensile fatigue behaviour of concrete; experiments, modeling and analyses," Heron, vol. 37, no. 1, pp. 3-79, 1992. 

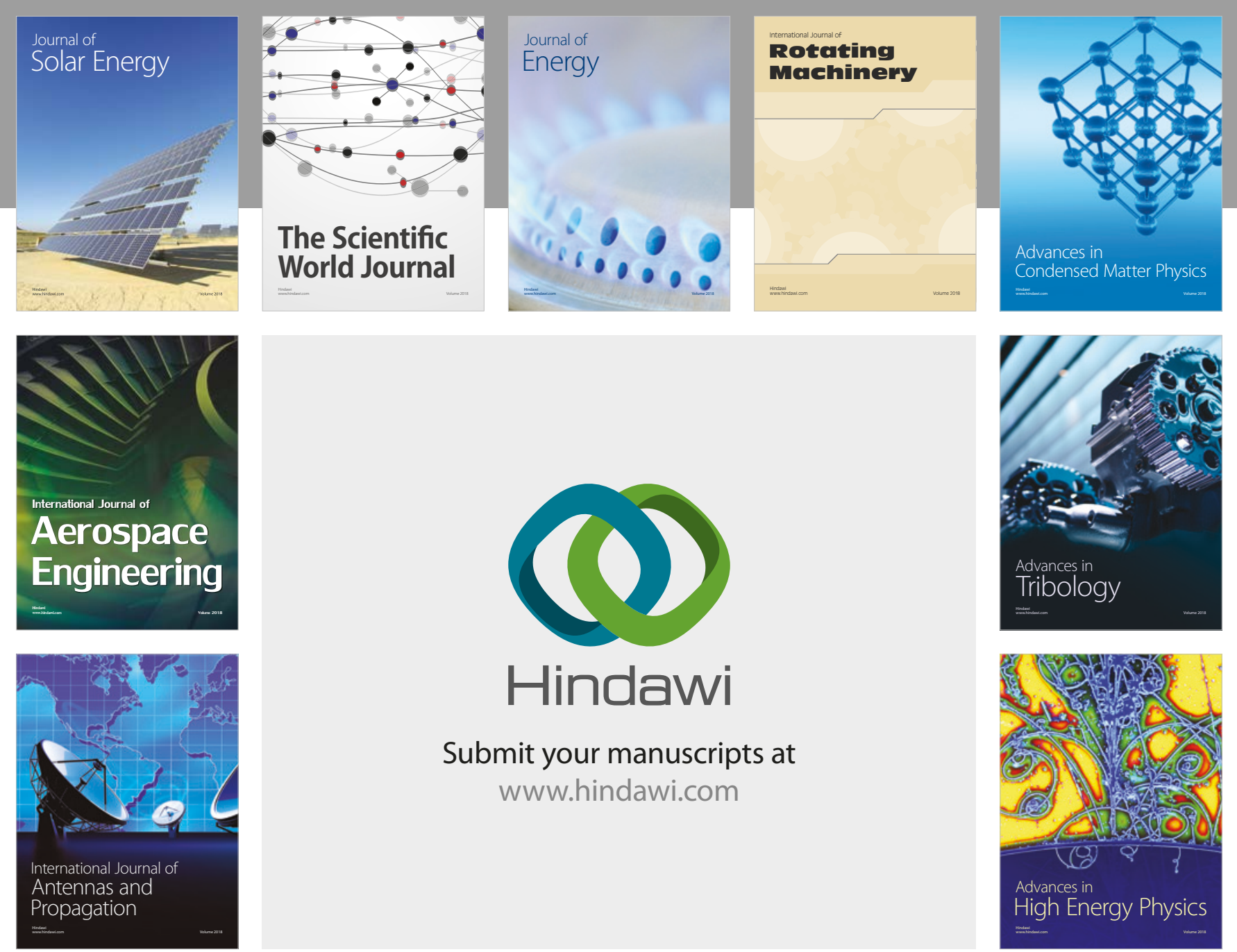

Submit your manuscripts at

www.hindawi.com
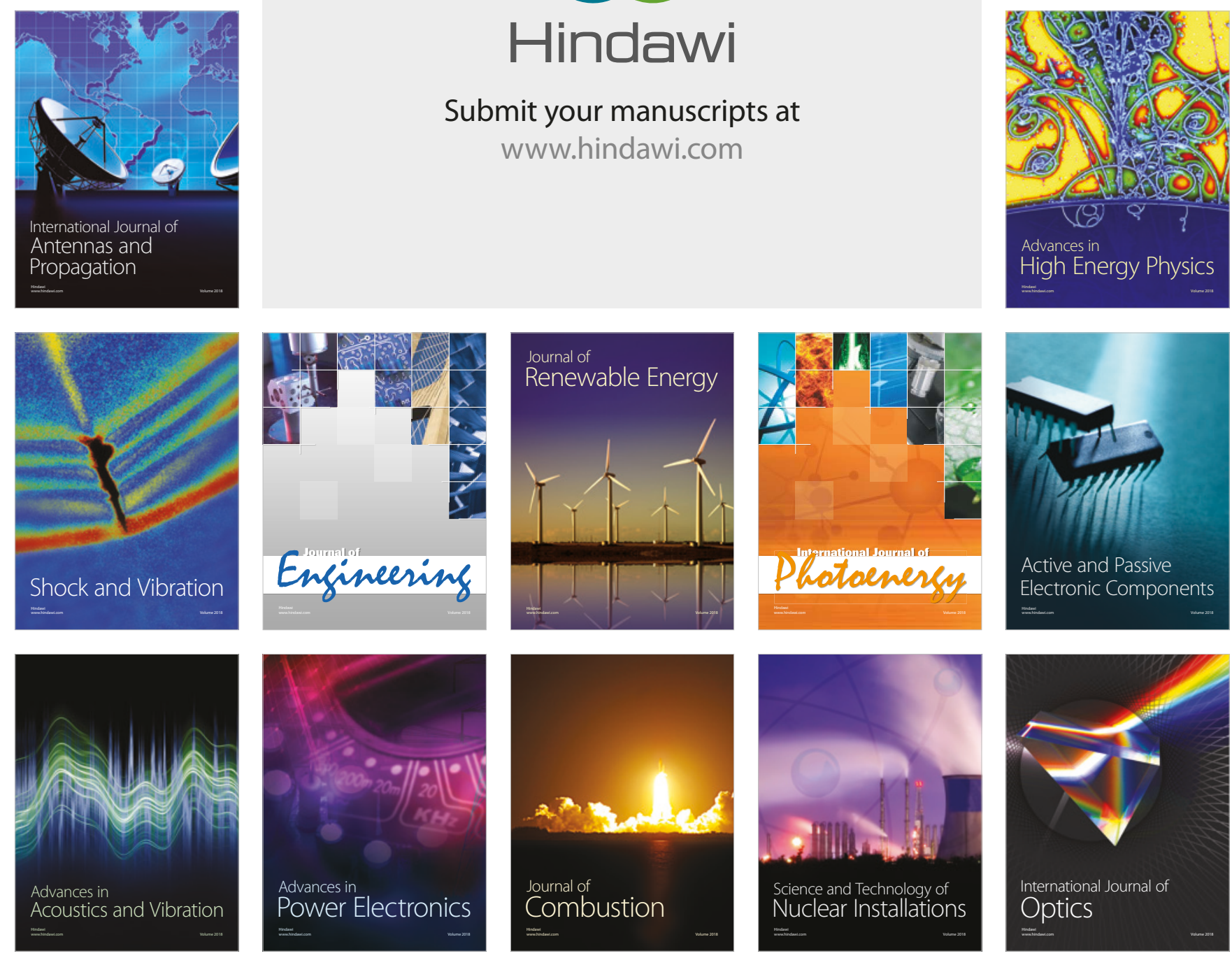